\title{
III. DERECHO POLÍTICO IBEROAMERICANO
}





\section{UNA MIRADA AL FEDERALISMO ARGENTINO: DISCURSO Y REALIDAD}

VÍCTOR BAZÁN 
SUMARIO

I. OBJETO DEL TRABAJO. II. EL ITINERARIO PROPUESTO. III. SUMARIAS APRECIACIONES GENERALES. IV. ACLARACIÓN HISTÓRICO-CONSTITUCIONAL. V. EL SISTEMA FEDERAL EN LA ARGENTINA. VI. FEDERALISMO Y REFORMA CONSTITUCIONAL DE 1994. VII. DE CIERTAS CUESTIONES DE INTERÉS (EN OCASIONES, CONFLICTIVAS) EN EL ÁMBITO DE LA ESTRUCTURA FEDERAL. VIII. APORTACIONES COMPLEMENTARIAS. IX. EPÍLOGO. 


\title{
UNA MIRADA AL FEDERALISMO ARGENTINO: DISCURSO Y REALIDAD
}

\author{
VÍCTOR BAZÁN* \\ Universidad Católica de Cuyo (San Juan, Argentina). \\ Universidad de Buenos Aires (UBA)
}

\section{OBJETO DEL TRABAJO}

Esencialmente, esta contribución pretende: $i$ ) exponer sucintamente la situación actual del federalismo argentino; ii) visualizar si en el ámbito pragmático han sido abastecidas las generosas pautas deparadas por la innovación constitucional de 1994 para robustecerlo; iii) detenernos en algunos problemas de interés surgentes de la dinámica federal, por ejemplo acerca de: a) si las constituciones provinciales pueden establecer más derechos que los contenidos en la Constitución nacional o dotar a los ya consagrados en ésta (y replicados en aquélla) de un caudal protectivo más fuerte, $b$ ) la «cláusula federal» incluida en determinados instrumentos internacionales sobre derechos humanos, como el Pacto de San José de Costa Rica, y c) el impacto del control de convencionalidad en las relaciones federales; $y$, por último, iv) visualizar las posibilidades del federalismo en el panorama institucional prospectivo de nuestro país.

\section{EL ITINERARIO PROPUESTO}

El recorrido propuesto comenzará, a modo de contextuación, con ciertas apreciaciones generales sobre ese fenómeno polifacético que es el federalismo.

\footnotetext{
* Catedrático de Derecho Constitucional y Director del Instituto de Derecho Constitucional, Procesal Constitucional y Derechos Humanos, Facultad de Derecho, Universidad Católica de Cuyo (San Juan, Argentina). Profesor de Posgrado, Universidad de Buenos Aires (UBA) y de otras Universidades argentinas y extranjeras.
} 
Seguidamente, y ya enfocándonos en el ámbito argentino, efectuaremos una aclaración preliminar en torno al ciclo constituyente originario desplegado entre 1853/1860. El texto histórico acondicionado en 1860 (con el ingreso de la Provincia de Buenos Aires a la Federación argentina) rige actualmente con las modificaciones de 1866, 1898, 1957 y 1994.

A continuación, brindaremos un panorama del sistema federal, para luego movernos hacia un análisis de la última reforma constitucional (1994) en lo atinente al federalismo y a la brecha existente entre las declaraciones normológicas contenidas al respecto en el texto de la Constitución nacional (C. N.) y la insuficiente o nula concreción pragmática de algunas de ellas.

Será momento entonces de examinar diversas cuestiones significativas en el marco de la estructura estadual federal: la autonomía municipal; la facultad de las provincias en punto a constituir regiones para su desarrollo económico y social; la potestad de aquéllas de realizar actividades en el ámbito internacional, por caso, la celebración de convenios internacionales con conocimiento del Congreso de la Nación y dentro de los límites fijados por el principio de «lealtad federal»; y el complejo interrogante sobre si los procesos de integración que el Estado nacional emprenda ad extra (v. gr., el Mercosur), resultan o no compatibles con la configuración estadual federal ad intra.

Más tarde abordaremos otros asuntos de interés, por ejemplo, el relativo a los reflejos anticipatorios del derecho público provincial vis-à-vis la C. N., en materias relevantes como los derechos fundamentales y los procesos constitucionales para efectivizarlos (además de otras imágenes como el carácter autonómico de los municipios y el dominio de los recursos naturales obrantes en su territorio); revisaremos brevemente si las constituciones provinciales pueden pautar más derechos que los contenidos en la Carta básica nacional o dotar a los consagrados en ésta de una protección jurídica más intensa; responderemos al interrogante acerca de qué hablamos cuando hablamos de la «cláusula federal» incluida en ciertos instrumentos internacionales en el campo de los derechos humanos, como la Convención Americana o Pacto de San José de Costa Rica; y efectuaremos una breve aproximación al control de convencionalidad y sus implicaciones en un Estado con estructura federal.

El cierre de la contribución vendrá de la mano de ciertas reflexiones de recapitulación, que se unirán a otras apreciaciones conclusivas volcadas en el nudo de la indagación que ponemos a consideración del lector.

\section{SUMARIAS APRECIACIONES GENERALES}

En primer lugar, es preciso evocar que el federalismo es un proceso dinámico y con numerosas fórmulas posibles de configuración. Tanto, que ha devenido 
clásica la puntualización de Friedrich en cuanto a que existen tantos federalismos como Estados federales con sus múltiples variantes ${ }^{1}$.

Sólo por citar una perspectiva autoral de la cual se infiere la nutrida constelación de modalidades federales, Wricht evoca el caso de un autor (Davis) que ha sostenido que el concepto de federalismo en los EE. UU. ha sido modificado o delimitado con tal profusión que es posible determinar y enumerar cuarenta y cuatro «tipos» diversos de federalismo. Al respecto, señala que Davis se pregunta si el concepto ha sido «envenenado lentamente mediante dosis crecientes de delimitación y cambio de terminología o enriquecido por nuevas ideas acerca de cómo los seres humanos se asocian entre sí» ${ }^{2}$, para añadir que cuanto «más hemos llegado a saber sobre él, menos satisfactoria y menos respetable se ha hecho la casi totalidad de nuestra tradición de teoría federal» ${ }^{3}$.

Para intentar comprender más cabalmente la lógica de funcionamiento del Estado federal en general, es útil servirse del ensayo analítico que realiza Lijphart al explorar el desempeño de treinta y seis países desde una doble dimensión de enfoque: la primera, del poder conjunto a partir del binomio ejecutivos-partidos, y la segunda — que es la que en realidad nos interesa remarcar aquí- del poder segmentado partiendo de la distinción federal-unitario, lo que en definitiva le permite catalogar los distintos supuestos entre democracia mayoritaria y democracia consensual ${ }^{4}$.

El examen de esta segunda dimensión: división del poder a partir de la distinción federal-unitario, que se corresponde con el modelo que el autor denomina "democracia consensual», es realizado tomando en cuenta las siguientes variables: i) división del poder, caracterizado en la democracia consensual por la no concentración de aquél e identificándose dos maneras básicas: el poder compartido y el poder dividido, este último mediante el federalismo y la descentralización; ii) parlamentos y congresos,

${ }^{1}$ FRIEDRICH, C., Teoría y realidad de la organización constitucional democrática, México D. F., Fondo de Cultura Económica, 1946, p. 207.

${ }^{2}$ DAVIS, S. R., The Federal Principle: A Journey Through Time in Quest of Meaning, Berkeley, California, University of California Press, 1978, p. 204; cit. por WRICHT, D. S., «Del federalismo a las relaciones intergubernamentales en los Estados Unidos de América: una nueva perspectiva de la actuación recíproca entre el gobierno nacional, estatal y local», Revista de Estudios Políticos, Nueva Época, $N^{\circ}$ 6, noviembre-diciembre de 1978, Madrid, Centro de Estudios Constitucionales (CEC), trad. de Faustino González González, p. 8.

${ }^{3}$ DAVIS, S. R., The Federal Principle: A Journey Through Time in Quest of Meaning, cit., p. 205; referido por WRICHT, D. S., «Del federalismo a las relaciones intergubernamentales en los Estados Unidos de América: una nueva perspectiva de la actuación recíproca entre el gobierno nacional, estatal y local», cit., ídem.

${ }^{4}$ LIJPHART, A., Modelos de democracia. Formas de gobierno y resultados en treinta y seis países, Barcelona, Ariel, 2000. 
respecto de lo cual afirma que el esquema consensual diseña un legislativo bicameral, con el poder dividido en dos diferentes cámaras; iii) constituciones normalmente rígidas que sólo pueden modificarse por medio de mayorías extraordinarias; iv) revisión judicial, en el contexto de sistemas en los que justamente las leyes están sometidas a semejante control por parte de los tribunales; y v) bancos centrales, cuya autonomía entraña una forma más de división del poder.

En lo particularmente tocante al federalismo y la experimentación institucional, el citado doctrinario subraya que uno de los aspectos de la autonomía de las unidades constituyentes de las federaciones es que éstas tienen sus propias constituciones, que pueden reformar libremente dentro de ciertos límites impuestos por las constituciones federales; lo que si bien teóricamente brinda la posibilidad de experimentar con diversas formas gubernativas, en la práctica se descubre un isomorfismo entre las formas gubernamentales centrales y las de las unidades componentes en cada país, como de las de éstas entre sí ${ }^{5}$.

Más allá de otras aportaciones, sostiene que «el federalismo es una organización política en la que las actividades del gobierno están divididas entre los gobiernos regionales y el gobierno central de modo que cada tipo de gobierno tiene ciertas actividades en las que toma decisiones finales» ${ }^{6}$.

\section{ACLARACIÓN HISTÓRICO-CONSTITUCIONAL}

El texto original de la Constitución nacional argentina data de 1853/1860, lapso de tiempo durante el cual se desplegó el poder constituyente originario ${ }^{7}$. Para comprender más acabadamente la apreciación en punto al mantenimiento del ciclo constituyente originario hasta $1860^{8}$, corresponde efectuar ciertas puntualizaciones.

Debe señalarse que el texto fundacional fue sancionado el 1 de mayo de 1853 , sin la concurrencia de la disidente Provincia de Buenos Aires, y vedaba expresamente su reforma hasta después de diez años de ser jurada. Sin perjuicio de ello, el 11 de noviembre de 1859 se celebró el denominado «Pacto de San José de Flores», por medio del cual Buenos Aires se declaró parte integrante de la Confederación Argentina.

5 Ibíd., p. 187.

${ }^{6}$ Ibíd., p. 178.

7 Median discrepancias doctrinarias sobre el punto, pues algunos autores consideran a la de 1860 como una reforma constitucional y no como el cierre del poder constituyente originario inaugurado en 1853.

8 Ver para ampliar sobre el particular, BIDART CAMPOS, G. J., Manual de la Constitución reformada, T' $T^{\circ}$, Buenos Aires, Ediar, 1996, pp. 375/376. 
En 1860, esto es, dentro del plazo de vigencia de la probibición de reforma y sobre la base del nuevo esquema de estructuración política — ya con Buenos Aires incorporada al mismo-, se llevó a cabo una importante revisión y complementación del texto de 1853 por la que, entre otras cosas, se dispuso que se utilizara la denominación «Nación Argentina»; se suprimió el mecanismo de control político del Congreso nacional sobre las provincias, al eliminarse el recaudo de aprobación por aquél de las constituciones locales; y se incorporó el importante art. 33 al texto constitucional, referido a los derechos implícitos 9.

La Constitución de 1853/60 rige hoy con las reformas de 1866, 1898, 1957 y la más reciente, una importante innovación operada en $1994^{10}$, que será particular objeto de estudio en esta contribución.

\section{EL SISTEMA FEDERAL EN LA ARGENTINA}

\section{Dos fuerzas en interacción}

Simplificando al extremo la cuestión, el federalismo argentino es una combinación de dos fuerzas: una centrípeta y la otra centrífuga. La primera, que va de la periferia hacia el centro, supone la existencia de una unidad en el Estado nacional argentino, que es soberano; mientras que la segunda, del centro hacia la periferia, implica la descentralización que permite la existencia de una pluralidad de provincias, que son autónomas.

Precisamente, el esquema federal pugna por establecer la unidad dentro de la variedad, funcionalizando los principios de autonomía y de participación.

El art. 1 de la Constitución argentina establece que la Nación argentina adopta para su gobierno la forma representativa, republicana y federal. Las dos primeras serían más bien formas de gobierno, mientras que la tercera es una forma de Estado, desde que supone una relación entre el poder y el territorio en la cual aquél —en principio— se descentraliza políticamente con base física o geográfica.

9 La aludida disposición reza: «Las declaraciones, derechos y garantías que enumera la Constitución, no serán entendidos como negación de otros derechos y garantías no enumerados; pero que nacen del principio de la soberanía del pueblo y de la forma republicana de gobierno».

${ }_{10}$ Para facilitar la lectura de esta contribución, reproduciremos las disposiciones constitucionales más importantes en torno a los temas centrales que aquí se abordan.

Dejamos sentado que, salvo aclaración en contrario, la utilización del énfasis en las normas transcriptas (tanto en el texto como en las notas a pie de página) no corresponderá al original, sino que será agregado por nuestra parte. 
Las provincias argentinas preexistieron a la Nación. No las veintitrés que hoy conforman el Estado argentino, sino las catorce que existían al momento de dar estructuración a aquélla. Luego se fueron agregando otras y provincializándose territorios nacionales ${ }^{11}$ hasta llegar al número actual.

Debe advertirse que si bien en general el federalismo argentino se inspira en el norteamericano (del que también tomó el modelo presidencialista), median diferencias importantes entre ambas configuraciones, por ejemplo, acerca de los disímiles niveles o gradaciones de descentralización que presentan y las particularidades que cada uno de los contextos históricos ofrecía al tiempo de sus respectivas vertebraciones.

Dicho de otro modo, no se trata de una copia mecánica o de un simple ejercicio de mímesis del diseño norteamericano.

En tren de comparar las estructuraciones federales de EE. UU. y la Argentina, se ha sostenido que la referencia a la Constitución estadounidense es relevante por cuanto sirve para explicar — siguiendo su proceso histórico— «que el sistema federal no siempre supone un proceso de descentralización territorial. En el caso de los Estados Unidos se trató, por el contrario, de un proceso de centralización de funciones y competencias desde los Estados preexistentes en los pactos de la unión perpetua y los artículos de la Confederación hacia un Estado federal (...). Nuestro país adoptó el federalismo en un contexto histórico diferente y más bien como una fórmula superadora de los antagonismos y luchas feroces entre unitarios y federales, siendo que los integrantes de este último bando no eran propiamente "federalistas" en el sentido del modelo norteamericano, sino independentistas que propugnaban una Confederación de estados soberanos cuyo fundamento principal era la oposición a Buenos Aires...» ${ }^{12}$.

\section{Otras características que exbibe la estructura estatal argentina}

A) En el Estado federal argentino coexisten la Nación, las provincias (dentro de éstas, los municipios) y la Ciudad Autónoma de Buenos Aires (CABA), que es la capital del país.

${ }^{11}$ El último en provincializarse fue el Territorio de Tierra del Fuego, Antártida e Islas del Atlántico Sur, por medio de la Ley N ${ }^{\circ} 23.775$, publicada el 15 de mayo de 1990 . Su constitución fue sancionada en 1991.

12 DALLA VIA, A. R., «Actualidad del federalismo argentino», en SERNA DE LA GARZA, J. M. (coord.), Federalismo y regionalismo. Memoria del VII Congreso Iberoamericano de Derecho Constitucional, México D. F., Instituto de Investigaciones Jurídicas (IIJ), Universidad Nacional Autónoma de México (UNAM), 2002, p. 58. 
En el marco de su autonomía, las provincias pueden sancionar sus propias Constituciones, obviamente respetando el sistema representativo y republicano como forma de gobierno, de acuerdo con lo ordenado por el art. $5^{13}$ de la C. N.

Tal vez la cuestión que, sintetizada al máximo, presentáramos líneas arriba en cuanto a la preexistencia de las provincias, permita comprender que la C. N. contenga una norma, el art. 121 en la numeración actual (inspirado en la Décima Enmienda ${ }^{14}$ de la Constitución de los EE. UU., que enuncia la doctrina del dual federalism), que establezca que «las provincias conservan todo el poder no delegado por esta constitución al gobierno federal, y el que expresamente se hayan reservado por pactos especiales al tiempo de su incorporación».

B) Siguiendo el hilo descriptivo que propone Bidart Campos, las relaciones típicas en la estructura federal son: i) de subordinación, en razón de la cual los ordenamientos locales deben ajustarse al ordenamiento federal; ii) de participación, por la que se concede cierto espacio a la colaboración de las provincias en las decisiones del gobierno federal, a través de la Cámara de Senadores; y iii) de coordinación, que delimita las competencias federales y provinciales mediante una distribución o un reparto ${ }^{15}$.

Precisamente en función de tal reparto existen, según el esquema que bosqueja el autor traído en cita en este punto ${ }^{16}$, las siguientes competencias: i) exclusivas del Estado federal (por ejemplo, la declaración de la intervención federal — punto que retomaremos infra-o del estado de sitio ${ }^{17}$ ); ii) exclusivas de las

${ }^{13}$ La cláusula en cuestión establece: «Cada provincia dictará para sí una Constitución bajo el sistema representativo republicano, de acuerdo con los principios, declaraciones y garantías de la Constitución nacional; y que asegure su administración de justicia, su régimen municipal, y la educación primaria. Bajo de estas condiciones el Gobierno federal, garante a cada provincia el goce y ejercicio de sus instituciones».

14 Tal Enmienda dice: «Los poderes no delegados a los Estados Unidos y no expresamente negados a los Estados son reservados a los Estados respectivamente o al pueblo».

15 BIDART CAMPOS, G. J., Manual de la Constitución reformada, To I, cit., pp. 440/441.

16 Ibíd., pp. 441/444.

17 El art. 23 de la C. N. establece: «En caso de conmoción interior o de ataque exterior que pongan en peligro el ejercicio de esta Constitución y de las autoridades creadas por ella, se declarará en estado de sitio la provincia o territorio en donde exista la perturbación del orden, quedando suspensas allí las garantías constitucionales. Pero durante esta suspensión no podrá el presidente de la República condenar por sí ni aplicar penas. Su poder se limitará en tal caso respecto de las personas, a arrestarlas o trasladarlas de un punto a otro de la Nación, si ellas no prefiriesen salir fuera del territorio argentino».

La declaración de estado de sitio en uno o varios puntos de la Nación en caso de conmoción interior es atribución del Congreso de la Nación, Cuerpo este último que también ostenta la potestad de aprobar o suspender el estado de sitio declarado, durante su receso, por el Poder Ejecutivo (art. 75, inc. 29). 
provincias (v. gr., dictar sus propias constituciones y legislaciones procesales); iii) concurrentes (por caso, establecer los impuestos indirectos internos - art. 75, inc. $2^{\circ}$, párr. $\left.1^{\circ}-\right)$, que pueden ser ejercidas tanto por el Estado federal como por las provincias; iv) excepcionales del Estado federal (v. gr., establecer impuestos directos en los términos del artículo constitucional 75 , inc. $2^{\circ}$, párr. $1^{\circ}$, y sólo por tiempo determinado); $v$ ) excepcionales de las provincias (por ejemplo, dictar los códigos de fondo mientras no los sancione o haya sancionado el Congreso de la Nación — cfr. interpretación del art. $126^{18}$ de la C. N.—); y vi) compartidas entre el Estado federal y las provincias, que requieren una «doble decisión integratoria» (por caso, cuando debe intervenir el Estado federal y una o más provincias participantes en la fijación de la Capital federal —art. $3^{19}$ de la C. N.—).

Finalmente, en relación con la distribución competencial, existiría una cuestión inadmisible y proscripta a toda instancia gubernamental (nacional o provincial, prohibición que - pensamos - se hace incluso extensiva, mutatis mutandi, a la CABA y a los municipios), en los términos del art. $29^{20}$ de la C. N.: la concesión de facultades extraordinarias o la suma del poder público a quien ejerza el correspondiente Poder Ejecutivo (presidente de la Nación, gobernador de provincia, jefe de gobierno de la CABA o intentente municipal).

C) En función de lo expresado anteriormente, los entes provinciales no pueden invadir los ámbitos de competencia federal ni derogar las fuentes normativas federales con un nivel jerárquico superior a las provinciales.

De hecho, el art. 31 de la Carta Básica enumera las fuentes que son ley suprema de la Nación: la propia C. N., las leyes de la Nación que en su consecuencia se dicten por el Congreso y los tratados con las potencias extranjeras. Al respecto la cláusula en cuestión especifica que «las autoridades de cada provincia están

De acuerdo con el art. 99, inc. 16, de la C. N., el Presidente de la Nación «[d]eclara en estado de sitio uno o varios puntos de la Nación, en caso de ataque exterior y por un término limitado, con acuerdo del Senado. En caso de conmoción interior sólo tiene esta facultad cuando el Congreso está en receso, porque es atribución que corresponde a este cuerpo (...)».

${ }_{18}$ Norma que, inter alia, determina que las provincias no pueden dictar los Códigos Civil, Comercial, Penal y de Minería, después de que el Congreso los haya sancionado.

19 Tal cláusula preceptúa: «Las autoridades que ejercen el Gobierno federal, residen en la ciudad que se declare Capital de la República por una ley especial del Congreso, previa cesión hecha por una o más legislaturas provinciales, del territorio que haya de federalizarse».

${ }^{20}$ Ese precepto, que no fue reformado en 1994, dispone: «El Congreso no puede conceder al Ejecutivo nacional, ni las Legislaturas provinciales a los gobernadores de provincia, facultades extraordinarias, ni la suma del poder público, ni otorgarles sumisiones o supremacías por las que la vida, el honor o las fortunas de los argentinos queden a merced de gobiernos o persona alguna. Actos de esta naturaleza llevan consigo una nulidad insanable, y sujetarán a los que los formulen, consientan o firmen, a la responsabilidad y pena de los infames traidores a la patria». 
obligadas a conformarse a ella, no obstante cualquiera disposición en contrario que contengan las leyes o constituciones provinciales» ${ }^{21}$.

Además, el art. 126 de la C. N. señala que las provincias no ejercen el poder delegado a la Nación. Añade la aludida norma que «[n]o pueden celebrar tratados parciales de carácter político; ni expedir leyes sobre comercio, o navegación interior o exterior; ni establecer aduanas provinciales; ni acuñar moneda; ni establecer bancos con facultad de emitir billetes, sin autorización del Congreso federal; ni dictar los Códigos Civil, Comercial, Penal y de Minería, después que el Congreso los haya sancionado; ni dictar especialmente leyes sobre ciudadanía y naturalización, bancarrotas, falsificación de moneda o documentos del Estado; ni establecer derechos de tonelaje; ni armar buques de guerra o levantar ejércitos, salvo el caso de invasión exterior o de un peligro tan inminente que no admita dilación dando luego cuenta al Gobierno federal; ni nombrar o recibir agentes extranjeros».

De su lado, y como lo marca el art. 128, ibíd., los gobernadores de provincia son agentes naturales del Gobierno federal para hacer cumplir la Constitución y las leyes de la Nación, las que deben ser respetadas de conformidad con el principio de lealtad federal que los entes subnacionales deben prodigar al Estado federal y que, por supuesto, éste también debe dispensar a aquéllos, en el marco de un federalismo cooperativo y de concertación ( $y$, por tanto, no competitivo).

Con todo, puede comprobarse empíricamente que si bien como se ha puntualizado existen normas que diseñan el reparto de competencias entre el Estado federal y las provincias, median ámbitos de compleja delimitación y espacios de actividad intergubernamental común entre ambas instancias. Por tanto, al hilo del dinamismo propio de todo federalismo, las relaciones y la distribución competencial al interior de la estructura estatal federal no son precisamente sencillas ni lineales.

Como mutatis mutandi expresa Fernández Segado, «la distribución de competencias no ha de verse sólo estáticamente, esto es, petrificada en la forma que le diera la Constitución en un momento histórico concreto, sino que debe verse adaptada dinámicamente a las respectivas exigencias de tiempo y lugar y, cuando sea preciso, debe seguir siendo desarrollada» ${ }^{22}$.

Ya desde antiguo la Corte Suprema de Justicia de la Nación (CSJN) sostuvo que debe evitar que se desnaturalicen el equilibrio y la armonía con que operan los poderes federales y provinciales, que actúan para ayudarse y no para destruirse.

${ }^{21}$ En su parte final, el artículo deja a salvo de tal principio general a los tratados ratificados por la Provincia de Buenos Aires después del Pacto de 11 de noviembre de 1859, es decir, el nombrado «Pacto de San José de Flores».

22 FERNÁNDEZ SEGADO, F., «Reflexiones críticas en torno al federalismo en América Latina», en SERNA DE LA GARZA, J. M. (coord.), Federalismo y regionalismo, cit., p. 137. 
Tal afirmación fue vertida en el consid. $9^{\circ}$ de la mayoría in re «Pucci, Jorge y otro c/ Braniff International» ${ }^{23}$, de 28 de octubre de 1975, aunque había sido anticipada en Fallos, 286:301 y sus citas.

D) En suma, en el escenario argentino conviven la Constitución nacional con las constituciones de cada uno de los veintitrés Estados provinciales (art. 123 de la C. N. ${ }^{24}$ ) e incluso con la de la CABA, la que si bien no es una provincia ni un municipio cuenta con un régimen de gobierno autónomo, con facultades propias de legislación y jurisdicción, y con un jefe de gobierno y legisladores elegidos directamente por el pueblo de la Ciudad (art. 129, ibíd.).

Lo expuesto implica que las provincias (al igual que la CABA) se dan sus propias instituciones locales y se rigen por ellas, eligiendo a sus gobernadores, legisladores y demás funcionarios, sin intervención del Gobierno federal (art. 122, ibíd.).

A su tiempo, aunque la sanción de los códigos de fondo en la distintas materias (civil, comercial, penal, etc.) corresponda al Congreso nacional, lo que significa que existe un solo cuerpo normativo sustantivo de cada temática para toda la Nación (art. 75, inc. 12, de la C. N. ${ }^{25}$ ); las provincias están facultadas para dictar sus códigos procesales o adjetivos (v. gr., procesal civil, procesal penal, procesal laboral) en sus respectivos ámbitos jurisdiccionales, los que cohabitan con los códigos procedimentales existentes en el ámbito federal (uno para cada espacio temático, por ejemplo, un Código Procesal Civil y Comercial de la Nación y un Código Procesal Penal de la Nación, aplicables en todo el país para la justicia federal).

Asimismo, cada provincia (también la CABA) estructura su propio sistema de administración de justicia, su modelo de control de constitucionalidad y sus específicos institutos procesales constitucionales, en lo concerniente a sus normativas locales. De allí que en nuestro país convivan el esquema judicial y de contralor de constitucionalidad federal, con los correspondientes a cada una de las provincias y a la CABA.

Tal realidad marca la existencia de un universo plural de instrumentos jurídicos, jurisdicciones y competencias que deben interactuar en la tipología de estructuración federal que da forma y textura al Estado argentino. Ello genera

${ }^{23}$ Fallos, 293:287. La mayoría estuvo compuesta por los ministros Masnatta, Levene (h.) y Ramella; mientras que por su voto se pronunció el juez Díaz Bialet.

${ }^{24}$ Dicha norma determina que cada provincia dicta su propia constitución, conforme a lo dispuesto por el aludido art. 5 de la C. N., «asegurando la autonomía municipal y reglando su alcance y contenido en el orden institucional, político, administrativo, económico y financiero».

25 Establece como atribución del Congreso de la Nación la de dictar los Códigos Civil, Comercial, Penal, de Minería, y del Trabajo y Seguridad Social (este último nunca fue sancionado). 
una compleja urdimbre de relaciones entre las distintas instancias políticas del sistema institucional, que por lo demás y en lo que tiene que ver con la configuración del gobierno, muestra un intenso tinte presidencialista.

\section{Somera presentación del principio de «lealtad federal»}

Ya hemos nombrado expresamente al principio de «lealtad federal». Pero, ¿de qué hablamos cuando hablamos de semejante pauta?

Para comenzar a responder la pregunta debemos transportarnos al sistema federal alemán, donde el principio en cuestión ha obtenido mayores niveles de elaboración doctrinaria y jurisprudencial y de aplicación pragmática ${ }^{26}$. Ya más recientemente se ha extendido también a otros sistemas estaduales de estructuración compuesta o compleja, por ejemplo Austria, Bélgica, Italia, Suiza, España.

La Bundestreue, como se denominó a la «lealtad federal» en Alemania, dio origen a un principio constitucional no escrito que emana del principio del Estado federal. Ese postulado presenta dos dimensiones: de una parte, el respeto obligado que los Länder deben rendir a la normativa federal; de otra, la improcedencia de que la Federación (Bund) fije políticas sin escuchar a aquéllos o impidiendo su participación en ellas.

Al respecto, Faller ha precisado que la relación entre el Bund y los Länder, así como la de éstos entre sí, «no se caracteriza por una vecindad aislada, sino que exige la cooperación, así como las atenciones recíprocas. Las relaciones políticas entre el Estado central y los Estados miembros están determinadas mediante una relación de confianza mutua, expresada en el concepto de "lealtad federal". Este principio pertenece a las normas constitucionales inmanentes de la Ley fundamental, que regulan las relaciones entre el Bund y los Länder» ${ }^{27}$.

De acuerdo con la jurisprudencia del Tribunal Constitucional Federal alemán (BVerfGE), el principio de lealtad federal exige que tanto la Federación como

${ }^{26}$ Se ha afirmado que ello ha ocurrido en el contexto del constitucionalismo alemán, «tanto en la Constitución del II Reich alemán de 1871 (incluso mucho antes, cuando ni siquiera puede hablarse propiamente de un Estado federal), como en la Constitución de Weimar de 1919, e incluso en la vigente Ley Fundamental de Bonn de 1949» (ÁLVAREZ ÁLVAREZ, L., «La función de la lealtad en el Estado autonómico», en Teoría y Realidad Constitucional, № 22, Madrid, Universidad Nacional de Educación a Distancia, 2008, p. 502).

27 FALLER, H. J., «El principio de la lealtad federal en el orden federativo de la República Federal de Alemania», Revista de Estudios Políticos, Nueva Época, № 16, julio-agosto de 1980, Madrid, CEC, trad. de Ramón García Cotarelo, p. 197. 
los Länder deban respetar de manera razonable en el ejercicio de sus competencias el interés común del Estado federal y los intereses de los Länder ${ }^{28}$.

Además, dicho principio se aplica también a las relaciones entre los Länder. El principio del comportamiento federal amistoso obliga a cada Land a respetar en el ejercicio de sus derechos, en lo necesario, los intereses de los otros Länder y de la Federación. El Land no debe insistir en la imposición de posturas que tengan un efecto limitador jurídico cuando con ello se alteren los intereses fundamentales de otro Land. En este principio constitucional del comportamiento federal amistoso radica sistemáticamente la frase no escrita de cláusula rebus sic stantibus en el Estado federal, que apunta a las relaciones constitucionales entre las partes de la «República Federal de Alemania» ${ }^{29}$.

Extrapolando mutatis mutandi aquellas apreciaciones al sistema argentino, y como se ha sostenido, el principio de lealtad federal «supone que en el juego armónico y dual de competencias federales y provinciales que, para su deslinde riguroso, pueden ofrecer duda, debe evitarse que tanto el gobierno federal como las provincias abusen en el ejercicio de esas competencias, tanto si son propias como si son compartidas o concurrentes; en sentido positivo, implica asumir una conducta federal leal, que tome en consideración los intereses del conjunto federativo, para alcanzar cooperativamente la funcionalidad de la estructura federal in totum» ${ }^{30}$.

Podríamos, por tanto, afirmar que se trata de un principio multidireccional, de respeto mutuo entre el Estado federal y las entidades subnacionales, y de éstas entre sí.

\section{FEDERALISMO Y REFORMA CONSTITUCIONAL DE 1994}

\section{El proclamado «fortalecimiento del federalismo»}

Precisamente una de las cuestiones centrales que aparecían en los discursos oficiales previos a la reforma constitucional de 1994, insistiendo en que se trataba de una de las ideas-fuerza de ésta, giraba en torno a la necesidad de

${ }^{28} B \operatorname{VerfGE} 32,199,218$; cit. por ROBBERS, G., «La contribución de la jurisdicción constitucional en la configuración del Estado federal en Alemania», Revista Catalana de Dret Públic, No 43, 2011, Barcelona, Generalitat de Catalunya, Escola d'Administració Pública de Catalunya, p. 5 , nota 27.

$29 B \operatorname{VerfGE} 34$, 216, 232; cit. en la obra mencionada en la llamada anterior, p. 9, nota 50.

30 BIDART CAMPOS, G. J., Manual de la Constitución reformada, To I, cit., p. 470. 
fortalecer el sistema federal, lo que quedó plasmado —al menos desde el plano normativo- por vía de tal innovación.

Entre ellas, las que enumeraremos a continuación.

\section{A) Vigorización del Senado nacional}

Secularmente, éste ha sido considerado como la Cámara que representa los intereses provinciales, aunque la redacción actual del precepto trasunte una presencia institucional importante de los partidos políticos.

Se ha llevado el número de senadores a tres (3) por cada una de ellas y la CABA (art. $54^{31}$ ), cualquiera sea el tenor cuantitativo poblacional de aquéllas, siendo ellos elegidos de manera directa por el cuerpo electoral ${ }^{32}$.

Asimismo, se asignó al Senado la calidad de Cámara de origen en proyectos de ley que contienen cuestiones importantes para las provincias: la ley convenio en materia de coparticipación federal (art. 75 , inc. $2^{\circ}$ ) y las iniciativas acerca del crecimiento armónico de la Nación y al poblamiento de su territorio y la promoción de políticas diferenciadas que tiendan a equilibrar el desigual desarrollo relativo de provincias y regiones (inc. 19 de tal artículo).

En un modelo bicameral como el argentino (Cámaras de Diputados y de Senadores), ser Cámara de origen es relevante pues puede terminar imponiendo su voluntad a la Cámara revisora (cfr. art. $81^{33}$ de la C. N.).

31 Dicha norma reza: «El Senado se compondrá de tres senadores por cada provincia y tres por la ciudad de Buenos Aires, elegidos en forma directa y conjunta, correspondiendo dos bancas al partido político que obtenga el mayor número de votos, y la restante al partido político que le siga en número de votos. Cada senador tendrá un voto».

32 Antes de la reforma constitucional eran 2 (dos) por Provincia y su elección era indirecta, a través de las legislaturas provinciales.

33 La nombrada cláusula prevé lo siguiente: «Ningún proyecto de ley desechado totalmente por una de las Cámaras podrá repetirse en las sesiones de aquel año. Ninguna de las Cámaras puede desechar totalmente un proyecto que hubiera tenido origen en ella y luego hubiese sido adicionado o enmendado por la Cámara revisora. Si el proyecto fuere objeto de adiciones o correcciones por la Cámara revisora, deberá indicarse el resultado de la votación a fin de establecer si tales adiciones o correcciones fueron realizadas por mayoría absoluta de los presentes o por las dos terceras partes de los presentes. La Cámara de origen podrá por mayoría absoluta de los presentes aprobar el proyecto con las adiciones o correcciones introducidas o insistir en la redacción originaria, a menos que las adiciones o correcciones las haya realizado la revisora por dos terceras partes de los presentes. En este último caso, el proyecto pasará al Poder Ejecutivo con las adiciones o correcciones de la Cámara revisora, salvo que la Cámara de origen insista en su redacción originaria con el voto de las dos terceras partes de los presentes. La Cámara de origen no podrá introducir nuevas adiciones o correcciones a las realizadas por la Cámara revisora». 
Por lo demás, se redujo la duración de los mandatos senatoriales de nueve (9) a seis (6) años.

B) Constitucionalización del sistema de coparticipación federal

Tal régimen, según se postula desde la literalidad constitucional, debe construirse sobre la base de las pautas de solidaridad social entre las provincias, implantándose la obligación de dictar una ley convenio al respecto, que deberá ser sancionada con la mayoría absoluta de la totalidad de los miembros de cada Cámara, no podrá ser modificada unilateralmente ni reglamentada y será aprobada por las provincias (art. 75 , inc. $2^{\circ}$, párr. $4^{\circ}$ ).

Además, en el inc. $3^{\circ}$ de tal disposición, la Carta magna instituye que el Congreso nacional está investido de la atribución de establecer y modificar asignaciones específicas de recursos coparticipables, por tiempo determinado, por ley especial aprobada por la mayoría absoluta de la totalidad de los miembros de cada Cámara.

Si bien la doctrina en general ha acogido con beneplácito (aunque en distintas gradaciones) la positivación constitucional de la coparticipación federal, no han faltado voces que la consideran un retroceso. En tal sentido, Dalla Via entiende que en la práctica produce un gran debilitamiento, pues aquella inclusión (a la que cataloga como una «actitud de sociologismo constitucional») equivale a un equívoco «blanqueo» de llevar a la norma una práctica originada en un desvío. Añade que la coparticipación federal es una de las instituciones que más han contribuido a acentuar la dependencia de las provincias al poder central y que nació como una patología ante la insuficiencia de nuestro sistema fiscal de atribución de competencias ${ }^{34}$.

C) Crecimiento armónico de la Nación

Se ha impuesto (fundamentalmente al Congreso de la Nación) el mandato constitucional consistente en proveer al crecimiento armónico de la Nación por el desarrollo equilibrado de provincias y regiones, dando prioridad a un grado equivalente del mismo, a la calidad de vida y a la igualdad de oportunidades en todo el territorio argentino.

${ }^{34}$ DALLA VIA, A. R., «Actualidad del federalismo argentino», cit., pp. 68/69. 
Ello surge de la conjugación del art. 75 , incs. $2^{\circ}$, tercer párrafo ${ }^{35}$, y 19, segundo párrafo ${ }^{36}$, con el art. 124 , ibíd., este último dentro del marco competencial de los gobiernos de provincia.

D) Sobre los establecimientos de «utilidad nacional»

Se ha concretado la delimitación de las competencias federal y provinciales en los lugares y establecimientos de «utilidad nacional», por conducto del art. 75, inc. 30 .

Tal norma dispone que corresponde al Congreso de la Nación «[e]jercer una legislación exclusiva en el territorio de la capital de la Nación y dictar la legislación necesaria para el cumplimiento de los fines específicos de los establecimientos de utilidad nacional en el territorio de la República. Las autoridades provinciales y municipales conservarán los poderes de policía e imposición sobre estos establecimientos, en tanto no interfieran en el cumplimiento de aquellos fines».

Entre otros puntos, cabe resaltar la incorporación de la expresión «fines específicos» de los establecimientos de utilidad nacional y la determinación en punto a que «[l]as autoridades provinciales y municipales conservarán los poderes de policía e imposición sobre estos establecimientos, en tanto no interfieran en el cumplimiento de aquellos fines». Ambas cuestiones, al menos desde la dimensión normativa, apuntan a fortalecer las autonomías provinciales y municipales.

En realidad, la nueva norma constitucional ha receptado el desarrollo jurisprudencial de la CSJN respecto de las facultades provinciales en los establecimientos de utilidad nacional ubicados dentro de su territorio.

Nos referimos a la jurisprudencia superadora del objetable criterio adoptado por el Alto Tribunal en «Hidronor, Hidroeléctrica Norpatagónica S. A. c/ Provincia del Neuquén» ${ }^{37}$, de 4 de diciembre de 1980 . En este caso, fallado en ejercicio de su jurisdicción originaria, admitió la demanda planteada y declaró por mayoría (integrada por los ministros Gabrielli y Black, más el voto concurrente del juez Rossi) la inconstitucionalidad de la Ley $N^{\circ} 769$ de la Provincia del Neu-

35 Tal tramo de la norma dispone: «La distribución entre la Nación, las provincias y la ciudad de Buenos Aires y entre éstas, se efectuará en relación directa a las competencias, servicios y funciones de cada una de ellas contemplando criterios objetivos de reparto; será equitativa, solidaria y dará prioridad al logro de un grado equivalente de desarrollo, calidad de vida e igualdad de oportunidades en todo el territorio nacional».

36 Ese segmento del inciso establece que el Congreso debe «(p)roveer al crecimiento armónico de la Nación y al poblamiento de su territorio; promover políticas diferenciadas que tiendan a equilibrar el desigual desarrollo relativo de provincias y regiones. Para estas iniciativas, el Senado será Cámara de origen».

37 Fallos, 302:1461. 
quén que había creado la municipalidad de tercera categoría en el pueblo «Villa El Chocón», Departamento de Confluencia y consiguientemente, determinó la nulidad del acto de asunción al cargo del comisionado municipal designado.

Se sostuvo que el entonces art. 67, inc. 27, de la C. N. (hoy — con modificaciones- corresponde al art. 75, inc. 30) atribuía al Congreso la facultad de «ejercer una legislación exclusiva» sobre los lugares adquiridos por compra o cesión, en cualquiera de las provincias, destinados a establecimientos de utilidad nacional, lo que debía entenderse en el sentido de que la facultad del Gobierno nacional a legislar — comprensiva de las de administrar y juzgar- en los lugares que la Constitución ha reservado para su jurisdicción en vista de la utilidad común que ellos revisten para la Nación, es única y no compartida, pues resulta inadmisible que, como está expresada, sea ejercida en forma concurrente por las legislaturas provinciales, toda vez que la exclusividad implica la negación del ejercicio simultáneo de otros poderes en esos lugares.

Por su parte, en sendas disidencias individuales se pronunciaron el ministro Frías y el ministro subrogante López, quienes propiciaban el rechazo de la demanda.

\section{E) Intervención federal}

En relación con este instituto, el art. 6 de la C. N. (no directamente modificado por la innovación constitucional de 1994 aunque sin duda impactado por otras normas que sí lo fueron), dispone: «El Gobierno federal interviene en el territorio de las provincias para garantir la forma republicana de gobierno, o repeler invasiones exteriores, y a requisición de sus autoridades constituidas para sostenerlas o restablecerlas, si hubiesen sido depuestas por la sedición, o por invasión de otra provincia».

Ya por medio de la citada reforma se ha pretendido imponer la premisa de que la intervención federal a las provincias (y a la CABA) es una figura extraordinaria, esclareciéndose que su declaración es competencia del Congreso de la Nación y que sólo excepcionalmente puede ser ejercida por el Poder Ejecutivo, teniendo en este caso el Cuerpo legislativo la potestad de aprobar o revocar la intervención decretada, durante su receso, por el Ejecutivo (cfr. arts. 75, inc. 31, y 99, inc. 20).

F) Autonomía municipal

Una importante decisión constitucional ha sido la de literalizar la obligatoriedad de que las provincias aseguren la autonomía de sus municipios, y regulen su 
alcance y contenido en los ámbitos institucional, político, administrativo, económico y financiero (art. 123 de la C. N., que debe leerse en línea con el art. 5, ibíd.).

Más adelante retornaremos a esta trascendente problemática, que aquí sólo dejamos anunciada.

G) Creación de regiones y celebración de convenios internacionales

Se trata de dos relevantes prerrogativas provinciales contenidas en el art. 124 de la C. N.

Nos referimos a la posibilidad de crear regiones para el desarrollo económico y social, y establecer órganos con facultades para el cumplimiento de sus fines. Sin embargo, ello no convierte a la región en una nueva instancia política dentro de la estructura de las relaciones federales.

También se ha dispensado a las provincias la prerrogativa de celebrar convenios internacionales, con ciertas lógicas limitaciones pues el manejo de la política exterior corresponde al Estado federal. En ese sentido, aquéllas pueden celebrar tales instrumentos internacionales (con conocimiento del Congreso nacional) en tanto y en cuanto, precisamente, no resulten incompatibles con la política exterior de la Nación y no afecten las facultades delegadas al Gobierno federal o el crédito público de la Nación.

Ambas potestades provinciales (creación de regiones y celebración de convenios internacionales) son tan importantes como potencialmente conflictivas, por lo que serán retomadas infra.

H) Sobre el dominio originario provincial de los recursos naturales

En un marco general de discusión, se ha explicado que «el principio de integridad territorial de las provincias rescata a favor de éstas el dominio y la jurisdicción de sus recursos naturales, su subsuelo, su mar territorial, su plataforma submarina, su espacio aéreo, sus ríos, lagos y aguas, sus caminos, las islas (cuando el álveo es provincial), las playas marinas y las riberas interiores de los ríos, etc. Las leyes del Estado federal opuestas a estos principios deben considerarse inconstitucionales» ${ }^{38}$ —énfasis del original-.

A su turno el art. 124, in fine, de la C. N. (con la redacción otorgada por la reforma de 1994) se encarga de determinar que «[c]orresponde a las provincias el dominio originario de los recursos naturales existentes en su territorio», aun-

38 BIDART CAMPOS, G. J., Manual de la Constitución reformada, To I, cit., p. 450. 
que nada dice sobre la exploración, la explotación y el aprovechamiento de tales recursos.

Sin duda, el tema ostenta un gran interés público y teje puntos de contacto con otras disposiciones constitucionales, como por ejemplo:

- el art. 41, referido al derecho de todos los habitantes a un ambiente sano, equilibrado, apto para el desarrollo humano y para que las actividades productivas satisfagan las necesidades presentes sin comprometer las de las generaciones futuras. Concretamente, la norma dispone que «[l]as autoridades proveerán a la protección de este derecho, a la utilización racional de los recursos naturales, a la preservación del patrimonio natural y cultural y de la diversidad biológica, y a la información y educación ambientales», para pasar a señalar que corresponde a la Nación dictar las normas que contengan los presupuestos mínimos de protección ${ }^{39}$, y a las provincias, las necesarias para complementarlas, sin que aquéllas alteren las jurisdicciones locales;

- el art. 75, inc. 17, con relación a los derechos de los pueblos indígenas argentinos, debiendo el Congreso de la Nación (y, añadimos por nuestra parte, todas las autoridades públicas competentes) asegurar su participación en la gestión referida a sus recursos naturales y a los demás intereses que los afecten, pudiendo las provincias ejercer concurrentemente ésta y las demás atribuciones desplegadas en la norma aludida; $y$

- el art. 75, inc. 19, que puede ser considerado como continente de una ambiciosa cláusula de «desarrollo humano» o «nueva cláusula del progreso» que complementa a la no menos generosa «cláusula del progreso» original, cobijada ahora en el inc. 18 de tal norma constitucional. En un marco de gran amplitud, aquel inciso impone al Congreso «[p]roveer lo conducente al desarrollo humano, al progreso económico con justicia social, a la productividad de la economía nacional, ...»; «[p]roveer al crecimiento armónico de la Nación (...); [y] promover políticas diferenciadas que tiendan a equilibrar el desigual desarrollo relativo de provincias y regiones...».

Con ser importante la incorporación al texto constitucional de la premisa referente a que corresponde a las provincias el dominio originario de los recursos naturales existentes en su territorio, en modo alguno la cuestión ha quedado zanjada, abriéndose numerosos frentes de discusión respecto de varias aristas directas y

39 Por medio de la Ley N $\mathrm{N}^{\circ} 25.675$ (publicada el 28 de noviembre de 2002), conocida como Ley General del Ambiente, se han establecido los presupuestos mínimos para el logro de una gestión sustentable y adecuada del ambiente, la preservación y protección de la diversidad biológica y la implementación del desarrollo sustentable. 
colaterales de un problema harto complejo, por ejemplo, sobre la relación no siempre lineal entre dominio y jurisdicción respecto de los recursos naturales.

En torno a tal cuestión, Bidart Campos expresa que el «dominio de las provincias sobre sus bienes no coincide con la jurisdicción; puede haber dominio sin jurisdicción, y así en materia de ríos las provincias tienen el dominio de los que corren por su territorio, sin perjuicio de la jurisdicción federal del Congreso con respecto a la navegación y al comercio interprovincial» ${ }^{40}$-remarcado del original-.

Frías, a su tiempo, ha puntualizado que el dominio se ejerce sobre las cosas, mientras la jurisdicción sobre las relaciones; añadiendo que «[e]l dominio lleva necesariamente a la jurisdicción si nada la limita o la excluye; la jurisdicción no lleva necesariamente al dominio» ${ }^{41}$.

Sea como fuera, es lícito concluir que la pauta consagrada en el tramo de cierre del artículo 124 constitucional, como hipótesis de mínima prefigura la obligación del gobierno federal de requerir el consentimiento de las provincias para disponer de los recursos naturales existentes en su territorio.

\section{I) $\mathrm{La} C A B A$}

Resulta también significativo que la reforma constitucional haya dispensado en el art. 129 un tratamiento explícito a la CABA, dotándola de un estatus jurídico sui generis ya que —en una simplificación máxima del tema- podría decirse que, al parecer, es más que un municipio pero menos que una provincia ${ }^{42}$.

La CABA es la sede de la Capital federal, y en definitiva es un nuevo sujeto de la relación federal que viene a sumarse a las restantes: el Estado federal, las provincias y, dentro de éstas, los municipios.

Como anticipábamos, la CABA ostenta un régimen de gobierno autónomo (acumulándose tal carácter autonómico a su condición de actual capital del país), con facultades propias de legislación y jurisdicción. Su jefe de gobierno es elegido directamente por el pueblo de la Ciudad, además de haber sancionado el 1 de octubre de 1996 su propia «Constitución», pese a que el art. 129 de la C. N. se refiere a la potestad de sancionar un «Estatuto Organizativo de sus instituciones».

40 BIDART CAMPOS, G. J., Manual de la Constitución reformada, T I, cit., p. 450.

${ }^{41}$ FRÍAS, P. J., Derecho público provincial, Buenos Aires, Depalma, 1985, p. 172.

${ }^{42}$ La discusión doctrinaria para encuadrar la naturaleza jurídica de la CABA ha sido intensa y se han imaginado numerosas modalidades. Por ejemplo, «ciudad autónoma», «ciudad-Estado», «municipio federado», «distrito autónomo», han sido sólo algunas de las etiquetas utilizadas al efecto. 
Es interesante la visión de Bidart Campos en cuanto a que el territorio de la Ciudad no está ya federalizado totalmente, sino sujeto a jurisdicción federal únicamente en lo que se refiere y vincula a los intereses que en ese territorio inviste el Estado federal, en razón de residir allí el gobierno federal y de estar situada la Capital federal; de lo que extrae que la jurisdicción federal es parcial y de naturaleza o sentido institucional y competencial, pero no territorial o geográfico, porque el territorio no es federal ni se federaliza ${ }^{43}$.

El citado autor aporta una percepción interesante en lo tocante a la posibilidad de intervención federal a la CABA, pero como Ciudad de Buenos Aires y no como Capital federal mientras lo siga siendo (arts. 75, inc. 31, y 99, inc. 20). En otras palabras, entiende que «individualizar a la ciudad — que por el art. 129 debe ser autónoma - ayuda a argumentar que si puede ser intervenida es porque su territorio no está federalizado y porque, a los fines de la intervención federal, se la ha equiparado a una provincia. Si la ciudad mantuviera su federalización mientras fuera capital, tal vez pudiera pensarse que, aun con autonomía», no sería susceptible de intervención en virtud de esa misma federalización territorial ${ }^{44}$.

En esa línea considera que cuenta con mayor asidero «imaginar que el gobierno autónomo de la Ciudad de Buenos Aires en un territorio que, aun siendo sede del gobierno federal y capital de la república, ya no está federalizado, es susceptible de ser intervenido porque, en virtud de este status, puede incurrir -al igual que las provincias- en las causales previstas en el art. 6 de la Constitución» ${ }^{45}$.

\section{Las palabras y los hechos}

En general, desde el plano normológico la reforma constitucional ha intentado producir un avance del federalismo. El obstáculo enraíza en la falta de correspondencia entre los postulados normativos y las concreciones fácticas.

Dicho de otra manera, aquel fortalecimiento del federalismo que se postulaba como uno de los puntos axiales de la reforma constitucional de 1994, no ha tenido encarnadura en el ámbito de la realidad.

Sólo por citar un ejemplo sintomático, según la Disposición transitoria Sexta de la Constitución, la ley convenio a la que hace referencia el art. 75 , inc. $2^{\circ}$, ibíd., en materia de coparticipación federal y la reglamentación del organismo fiscal federal, deberían haber sido establecidos antes de la funalización del año 1996.

\footnotetext{
43 BIDART CAMPOS, G. J., Manual de la Constitución reformada, Tº I, cit., p. 456.

44 Ídem.

45 Ídem.
} 
Tal mandato constitucional no se ha cumplido, e incluso al presente (primer semestre de 2013) semejante ley convenio no ha sido aún sancionada y nada hace presagiar que pudiera serlo en un futuro próximo ${ }^{46}$.

En consecuencia, más allá de la impronta aspiracional del constituyente en pro de robustecer las estructuras provinciales, empíricamente ello no ha acaecido. Antes bien, ha aumentado el centralismo (algún autor habla de la macrocefalia del «puerto», o sea, de Buenos Aires ${ }^{47}$ ) y, sobre todo, se ha incrementado la subordinación financiera y económica de la mayoría de las provincias a la Nación.

Conectado con ello, tampoco se ha atenuado el poder presidencial como se pregonaba en su momento. Todo lo contrario, el Ejecutivo concentra más poderes y facultades, avanza sobre el Legislativo dictando decretos de necesidad y urgencia y, en no pocas ocasiones, presiona al Poder Judicial en temas de trascendencia institucional e intenta limitar su accionar e independencia ${ }^{48}$.

${ }^{46}$ Continúa rigiendo en la materia la Ley No 23.548, publicada el 26 de enero de 1988, que establecía a partir del 1 de enero de 1988 el «Régimen Transitorio de Distribución de Recursos Fiscales entre la nación y las provincias» — remarcado agregado-.

Por la fecha de su sanción, no incluyó en su texto primigenio a la CABA ni a la Provincia de Tierra del Fuego, Antártida e Islas del Atlántico Sur (como vimos, último Territorio nacional en ser provincializado). De hecho, el art. 8 de la ley se refiere a «la Municipalidad de la Ciudad de Buenos Aires y al Territorio nacional de Tierra del Fuego».

Ya por medio del art. 1 del Decreto $\mathrm{N}^{\circ} 705 / 2003$ (publicado el 27 de marzo de 2003), se establece desde el 1 de enero de 2003 , la participación correspondiente a la $C A B A$ en el monto total recaudado.

Por su parte, el art. 1 del Decreto $\mathrm{N}^{\circ} 2.456 / 90$ (publicado el 29 de noviembre de 1990), texto según el art. 2 del Decreto $\mathrm{N}^{\circ}$ 702/99 (publicado el 7 de julio de 1999), fija la participación que le corresponde a la Provincia de Tierra del Fuego, Antártida e Islas del Atlántico Sur en el monto total de la masa de fondos a distribuir.

${ }^{47} \mathrm{Al}$ respecto se ha dicho: «El federalismo argentino es el resultado de un proceso histórico particular de formación de una alianza entre la macrocefálica Buenos Aires y un cuerpo que no ha guardado proporción. Desde la constitución del Virreinato del Río de la Plata, en 1778, el puerto y su ciudad se tomaron revancha de Lima y del privilegio que el interior mantuvo durante casi todo el siglo XVIII, con el comercio de la plata. A partir de entonces, Buenos Aires ha sido el centro neurálgico del país,...» —énfasis agregado- (Muchnik, D., «El ilusorio federalismo argentino", Le Monde Diplomatique; Fuente: http://www.insumisos.com/diplo/NODE/3413. HTM).

48 Basta con reparar en que recientemente el Poder Ejecutivo envió al Congreso una batería de seis (6) proyectos de ley en nombre de la «democratización de la Justicia», respecto de los cuales no pocos opinan que en realidad lo que se pretende es la domesticación de la Justicia. Los tres más conflictivos, ya aprobados y, por tanto, derecho vigente, son:

i) la Ley $\mathrm{N}^{\circ} 26.855$ (B. O. de 27 de mayo de 2013) que, entre otras, reforma la ley del Consejo de la Magistratura, órgano que aumenta el número de sus miembros trepando a diecinueve (19); disminuye las mayorías exigidas para tomar sus decisiones (v. gr., imponer sanciones disciplinarias, desencadenar el proceso de remoción que llevará adelante el Jurado de Enjui- 
En suma, al desfigurarse fácticamente el propósito perseguido por el constituyente en orden a reforzar la solidez de la estructura federal, paralelamente crece el déficit democrático. Es que, como advierte Fernández Segado ${ }^{49}$, si la estructura federal se encuentra en íntima conexión con la democracia, «que en el Estado federal no se proyecta sobre una única organización, sino sobre una pluralidad de centros de decisión», se comprende que el déficit democrático esté «estrechamente unido a la desnaturalización del sistema federal, no pudiendo, a la inversa, operar el sistema federal como instrumento democratizador del poder, contribuyendo de este modo a la vivificación de la democracia, una de las más caracterizadas funciones del federalismo, como bien advierte Schambeck ${ }^{50}{ }$.

ciamiento); acrecienta su poder y recibe una nueva dosis de politización como consecuencia de la previsión relativa a la elección por sufragio universal de sus integrantes jueces, abogados y académicos. Debe aclararse que tal Ley N. 26.855 fue declarada inconstitucional por la CSJN en el caso «Rizzo, Jorge Gabriel», de 18 de junio de 2013, con lo que ha quedado virtualmente desactivada;

ii) la Ley $\mathrm{N}^{\circ} 26.854$ (B. O. de 30 de abril de 2013), referida a las medidas cautelares en las causas en las que es parte o interviene el Estado Nacional o sus entes descentralizados, ámbito normativo en el que se establecen limitaciones a los jueces para el dictado de semejantes medidas en contra de aquéllos, además de restricciones temporales al mantenimiento de ellas, lo que a priori aparece como una vulneración de los derechos y principios de acceso a la justicia, debido proceso e igualdad ante la ley en desmedro de los justiciables; $y$

iii) la Ley $\mathrm{N}^{\circ} 26.853$ (B. O. de 17 de mayo de 2013) que crea las siguientes tres (3) Cámaras: a) Federal de Casación en lo Contencioso Administrativo Federal; b) Federal y Nacional de Casación del Trabajo y la Seguridad Social; y c) Federal y Nacional de Casación en lo Civil y Comercial. Éstas están llamadas a conocer y decidir los recursos de casación, inconstitucionalidad y revisión interpuestos, respectivamente, contra las sentencias dictadas por la Cámara Nacional de Apelaciones en lo Contencioso Administrativo Federal y por las demás Cámaras Federales de Apelación del país en causas contencioso-administrativas federales; la Cámara Nacional de Apelaciones del Trabajo y la Cámara Federal de Apelaciones de la Seguridad Social; y las Cámaras Federales y la Nacional de Apelaciones en lo Civil y Comercial Federal, la Cámara Nacional de Apelaciones en lo Civil y la Cámara Nacional de Apelaciones en lo Comercial. En síntesis, esta reforma genera una nueva instancia burocrática en la ya larga senda que debe recorrer el interesado en busca de justicia, con el consiguiente impacto en la duración de los procesos, además de intentar quitar poder no sólo a las cámaras cuyas sentencias serán revisadas por las nuevas estructuras jurisdiccionales, sino también a la propia CSJN.

49 FERNÁNDEZ SEGADO, F., «Reflexiones críticas en torno al federalismo en América latina», cit., p. 111.

50 SCHAMBECK, H., «Posibilidades y límites del federalismo», Revista de Documentación Administrativa, N. ${ }^{\circ}$ 193, enero-marzo de 1982, Madrid, trad. de Joaquín Abellán, p. 87.

Hemos consultado la fuente original y en el párrafo al que alude Fernández Segado (vid. nota anterior), Schambeck afirma: «El federalismo puede contribuir a la vivificación de la democracia, puesto que con la construcción federal del Estado se problematizan los sectores más cercanos de la 


\section{Lo deseable en materia de coparticipación federal}

Naturalmente, lo anhelable es que — voluntad politica mediante- se logren consensos básicos para formular criterios objetivos de reparto sobre una plataforma de solidaridad y proporcionalidad. Ello, para abastecer las exigencias de la seguridad jurídica, morigerar las desigualdades y asimetrías y resguardar debidamente los postulados de un federalismo de concertación (o convergencia) y participativo.

Como es de suponer, lo anterior no implica obviar la posibilidad de que se contemple en aquel instrumento un razonable margen de flexibilidad en función de la dinámica política y las adaptaciones que — inter alia — impongan los cambios y nuevos requerimientos sociales, económicos, territoriales, que germinen.

Tal vez lo precedentemente expuesto pueda aportar en favor de que se atenúe la tentación de los gobiernos centrales de utilizar arbitrariamente la asignación de recursos como premios o castigos, de acuerdo con la textura político-partidaria de las ocasionales autoridades provinciales, supeditándolos respectivamente a la alineación o al enfrentamiento de éstas con el partido, alianza o frente políticos que circunstancialmente guíe el timón gubernativo nacional.

Por cierto, no ignoramos las dificultades que se corporizan a la hora de intentar compatibilizar los intereses de los actores comprometidos en la cuestión para lograr la aplicación de criterios racionales y ecuánimes de distribución de la masa coparticipable. Basta repasar lo que narrábamos supra con la ausente ley convenio en materia de coparticipación federal que debió haber sido dictada hacia finales de 1996, sin que hasta el momento haya visto la luz.

\section{DE CIERTAS CUESTIONES DE INTERÉS (EN OCASIONES, CONFLICTIVAS) EN EL ÁMBITO DE LA ESTRUCTURA FEDERAL}

\section{Introito}

Brindado un panorama general de la modificación constitucional respecto de diversos aspectos del federalismo, nos detendremos aquí en un conjunto de temas que ofrecen perfiles dignos de ser abordados con alguna profundidad, lo que intentaremos concretar siempre dentro de las lógicas limitaciones de espacio de este ensayo.

Nos referimos a: i) el mandato constitucional dirigido a las provincias en punto a asegurar y plasmar la autonomía de sus municipios; ii) la regionalización

vida pública, con lo que la formación de la opinión y de la voluntad políticas se sitúa sobre una base más amplia» — remarcado del original-. 
ad intra; iii) la actividad internacional de las provincias; y iv) el impacto que una intensificación de los ligámenes integracionales que el Estado nacional decidiera llevar adelante (por ejemplo en el contexto del Mercosur) podrían eventualmente ocasionar en los escenarios provinciales.

Pasamos a desarrollar los citados problemas.

\section{Reforma constitucional y autonomía municipal}

A) Como señalábamos, la reforma de 1994 plasmó en el art. 123 de la C. N. un encargo mandatorio a las provincias en punto a garantizar la autonomía de sus municipios, regulando el alcance de ésta en los planos institucional, político, administrativo, económico y financiero.

En puridad, se ha constitucionalizado el criterio jurisprudencial forjado por la CSJN a partir del caso «Rivademar, Ángela D. B. Martínez Galván de c/ Municipalidad de Rosario» ${ }^{51}$, de 21 de marzo de 1989, que zanjó la discusión sobre la naturaleza jurídica de los municipios, concluyendo que éstos no son entes autárquicos.

De hecho, en el consid. $8^{\circ}$ de tal pronunciamiento, la Corte expresó que «mal se avienen con el concepto de autarquía diversos caracteres de los municipios, tales como su origen constitucional frente al meramente legal de las entidades autárquicas; la existencia de una base sociológica constituida por la población de la comuna, ausente en tales entidades; la imposibilidad de su supresión o desaparición, dado que la Constitución asegura su existencia, lo que tampoco ocurre con los entes autárquicos; el carácter de legislación local de las ordenanzas municipales frente al de resoluciones administrativas de las emanadas de las autoridades de las entidades autárquicas; el carácter de personas jurídicas de derecho público y de carácter necesario de los municipios (art. 33, Cód. Civil, y especialmente la distinción hecha en el texto originario de Vélez Sársfield), frente al carácter posible o contingente de los entes autárquicos; el alcance de sus resoluciones, que comprende a todos los habitantes de su circunscripción territorial, y no sólo a las personas vinculadas, como en las entidades autárquicas; la posibilidad de creación de entidades autárquicas en los municipios, ya que no parece posible que una entidad autárquica cree a otra entidad autárquica dependiente de ella; y la elección popular de sus autoridades, inconcebible en las entidades autárquicas» — remarcado añadido- .

B) Al comentar el art. 123 de la C. N., Quiroga Lavié destaca que la Constitución no ha consagrado la autonomía absoluta del régimen municipal, sino

51 Fallos, 312:326. El fallo fue suscripto de modo unánime por los ministros Caballero, Belluscio, Fayt, Petracchi y Bacqué. 
solamente su principio. Además, lo ha condicionado, en su alcance y contenido, a las reglas que el orden institucional, político, administrativo, económico y financiero de cada provincia establezca. No podía ser de otra forma, porque de lo contrario, en aras de la autonomía municipal, se podría haber restringido la autonomía institucional de las provincias, que tiene rango superior ${ }^{52}$.

En sentido afín, Natale revela que el alcance y el contenido de la autonomía serán definidos por cada provincia. Ellas no podrán ignorar el mandato constitucional ni limitarlo al extremo de desnaturalizarlo [ya que] ese concepto está definido por la doctrina y las provincias deberán admitirlo para que la Nación les asegure su propio gobierno ${ }^{53}$.

Frías, a su tiempo, sostiene que la municipalización de la vida pública argentina es una de las consecuencias notables de la descentralización, añadiendo que el proceso concierne a lo institucional pero también a la cultura política, para luego advertir que la autonomía municipal se afianzó primero en la doctrina, tardíamente en la jurisprudencia de la CSJN, antes en el ciclo constituyente provincial y luego ha sido coronada por la reforma nacional de $1994^{54}$.

Rosatti señala que el municipio es un ente que «tiende» a la autonomía, entendiéndose por autonomía (en su acepción «plena») el reconocimiento de las siguientes atribuciones ${ }^{55}$ :

- Autonormatividad constituyente, o sea, capacidad para darse u otorgarse la propia norma fundamental;

- autocefalia, es decir, capacidad para elegir sus propias autoridades;

- autarcia o autarquía, esto es, autosatisfacción económica y financiera derivada de la posesión de recursos propios y complementada con la posibilidad de disponer de ellos;

- materia propia, o sea el reconocimiento de un contenido específico con facultades de legislación, ejecución y jurisdicción; y

- autodeterminación política, o sea el reconocimiento de garantías frente a las presiones políticas o económicas que, realizadas desde una instancia de decisión más abarcativa, puedan condicionar el ejercicio de las atribuciones descriptas precedentemente.

52 QUIROGA LAVIÉ, H., Constitución Argentina comentada, Buenos Aires, Zavalía, pp. 719/720.

53 NATALE, A. L., Comentarios sobre la Constitución, Buenos Aires, Depalma, 1995, p. 173.

${ }^{54}$ FRÍAS, P. J., El proceso federal argentino II, Córdoba (Argentina), Ediciones del Copista, 1998, p. 84 .

55 ROSATTI, H. D., «El federalismo en la reforma», en AA. VV., La reforma de la Constitución, explicada por miembros de la Comisión redactora, Santa Fe (Argentina), Rubinzal-Culzoni, 1994, p. 223. 
Ello lleva al autor citado en último término a concluir que no todos los municipios deben gozar del mismo status jurídico pues habrá algunos con autonomía plena (con las cinco atribuciones señaladas), y otros con una semiplena o relativa (pudiendo, por ejemplo, carecer de autonormatividad constituyente) ${ }^{56}$.

Bidart Campos proclama también la importancia de la autonomía económico-financiera de los municipios, al evocar que si bien durante un tiempo había interpretado como admisible que los municipios de provincia ejercieran por «delegación» de la provincia determinadas competencias tributarias, posteriormente evolucionó hasta reconocer - incluso antes de la reforma constitucional de 1994-que los municipios investían poder tributario originario o propio. El citado autor destaca que hoy el art. 123 disipa las dudas, porque obliga a las provincias a reglar el alcance y el contenido de la autonomía municipal en el orden económico y financiero, base constitucional federal que lo lleva a sostener que cada constitución provincial ha de reconocer a cada municipio de su jurisdicción — según sea la categoría de este municipio - un espacio variable para crear tributos, lo que implica que desde la Constitución federal se da sustento al poder impositivo originario de los municipios. A su tiempo, aclara que son las constituciones provinciales las que deben deslindar el poder impositivo local entre la propia provincia y los municipios, utilizando permisiones y prohibiciones respecto de los últimos, pero sin que puedan inhibir o cancelar totalmente el poder tributario municipal ${ }^{57}$.

Para concluir el circuito doctrinario ilustrativo sobre el tópico que tratamos, Sánchez Morón considera — mutatis mutandi - que cuando se asevera que la autonomía de los municipios es meramente administrativa, se está confundiendo la significación teleológica y el fundamento organizativo de la autonomía municipal con la naturaleza de las funciones que los municipios han de desempeñar; añadiendo que lo esencial de la autonomía política de un ente es la correspondencia entre la voluntad colectiva de la comunidad y la acción pública de las organizaciones representativas de éstas que tienen encomendada la gestión de una parte de sus intereses, señalando que la representatividad de los entes municipales es representatividad política ${ }^{58}$.

56 Ídem.

57 BIDART CAMPOS, G. J., Manual de la Constitución reformada, To II, Buenos Aires, Ediar, 1997, p. 181.

58 SÁNCHEZ MORÓN, M., La autonomía local. Antecedentes históricos y significado constitucional, 1. ${ }^{a}$ ed., Monografías, Servicio de Publicaciones de la Facultad de Derecho, Universidad Complutense, Madrid, Civitas, 1990, p. 175.

Al respecto, es dable señalar que en la Constitución española de 1978, el art. 137 prescribe: «El Estado se organiza territorialmente en municipios, en provincias y en las Comunidades Autó- 
C) En la senda argumental que transitamos, podemos concluir que la autonomía municipal no puede entenderse en términos absolutos, ya que para respetar el mandato de la C. N. el sistema municipal instaurado (o por implementar) en cada provincia deberá adaptarse a lo que preceptúen sus respectivas constituciones y, en su caso, las normativas que pudieran emanar los propios poderes legislativos provinciales.

Por citar a modo de ejemplo otro fallo de la CSJN en la materia, se observa que in re «Telefónica de Argentina c/ Municipalidad de Chascomús s/ Acción declarativa», de 18 de abril de 1997, ha señalado que las prerrogativas de los municipios derivan de las correspondientes a las provincias a las que pertenecen (consid. $7^{\circ}$, párr. $2^{\circ}$ ), pasando a agregar que «el régimen municipal que los Constituyentes reconocieron como esencial base de la organización politica argentina al consagrarlo como requisito de la autonomía provincial (art. $5^{\circ}$ ), consiste en la Administración de aquellas materias que conciernen únicamente a los habitantes de un distrito o lugar particular sin que afecte directamente a la Nación en su conjunto y, por lo tanto, debe estar investido de la capacidad necesaria para fijar las normas de buena vecindad, ornato, higiene, vialidad, moralidad, etc. de la Comuna y del poder de preceptuar sanciones correccionales para las infracciones de las mismas...» ${ }^{59}$ (consid. 10, in fine) —énfasis nuestro-.

En definitiva, lo cierto es que en nuestro país, luego de la reforma constitucional de 1994 y conforme al art. 123, los municipios deben tener un régimen mínimo de organización y administración propias, y de autonomía económica y financiera. Los órdenes de autonomía previstos en la mencionada norma constitucional suponen: i) el institucional, la potestad de los municipios de dictarse su propia carta fundamental por medio de una convención convocada al efecto; ii) el político, la capacidad de nominar a sus autoridades y regirse por ellas; iii) el administrativo, la autorización para gestionar y organizar, inter alia, los intereses, servicios y obras locales; y iv) el económico-financiero, la habilitación para diseñar su modelo rentístico, administrar su presupuesto, recursos propios y la inversión de ellos.

nomas que se constituyan. Todas estas entidades gozan de autonomía para la gestión de sus propios intereses». A su turno, el art. 140, ibíd., dispone: «La Constitución garantiza la autonomía de los municipios. Éstos gozan de personalidad jurídica plena. Su gobierno y administración corresponde a sus respectivos Ayuntamientos, integrados por los Alcaldes y los Concejales...».

59 Fallos, 320:619. Votaron coincidentemente los jueces Moliné O'Connor, Fayt, Belluscio, Boggiano, López, Bossert y Vázquez. 


\section{La regionalización}

A) El aludido artículo 124 constitucional acuerda a las provincias la facultad de crear regiones para el desarrollo económico y social, y establecer órganos con facultades para el cumplimiento de sus fines. Tal premisa debe leerse en línea con el art. 125, parte inicial, ibíd., que permite a las provincias la celebración de tratados parciales para fines de administración de justicia, de intereses económicos y trabajos de utilidad común, con conocimiento del Congreso; y con el art. 126, ibíd., que paralelamente les proscribe ejercer el poder delegado a la Nación y la celebración de tratados parciales de carácter político.

De tal trama normativa surge que la región no es una nueva instancia política en el sistema institucional argentino. Pero sin duda, es una importante herramienta de oxigenación federal, mas siempre como vehículo descentralizador, es decir, como advierte Hernández, no destinada a centralizar el país o violar las autonomías provinciales y municipales ${ }^{60}$.

B) Aprovechamos este segmento del trabajo para reiterar nuestra posición en punto a que la creación de regiones en los términos del art. 124 de la Constitución federal es una facultad provincial y no del gobierno nacional, lo que obviamente no significa que éste deba desentenderse del proceso de regionalización, pues otra de las innovaciones vehiculadas por la reforma de 1994 y, en este caso, trasvasada al art. 75 , inc. 19 , párr. $2^{\circ}$, es —como vimos- la atribución conferida al Congreso en punto a proveer al crecimiento armónico de la Nación y promover políticas diferenciadas que tiendan a equilibrar el desigual desarrollo relativo de provincias y regiones, iniciativas para las cuales el Senado será Cámara de origen.

En otras palabras, las regiones no pueden ser pergeñadas por ley del Congreso y de espaldas a las provincias o en contra de la voluntad de éstas, pues como ha advertido Gelli, «[n]o se trata de que el Estado federal planifique una superestructura compuesta por regiones por sobre las provincias que implique, en los hechos, un corrimiento de los límites de éstas. Por el contrario, la regionalización se constituye en un instrumento de los entes locales para solucionar problemas comunes, maximizando las ventajas comparativas de cada una de las provincias que acuerdan crear una región, aunque sólo pueden hacerlo en materia económica y social...» ${ }^{61}$.

${ }^{60}$ HERNÁNDEZ, A. M., Integración y globalización: rol de las regiones, provincias y municipios, Buenos Aires, Depalma, 2000, p. 41.

61 GELLI, M. A., Constitución de la Nación Argentina. Comentada y concordada, To II, 4. ${ }^{\mathrm{a}}$ ed. ampl. y actualiz., Buenos Aires, La Ley, 2008, p. 609. 
Por lo demás, la política de regionalización ad intra y ad extra podría coadyuvar a la consecución de grados más avanzados de cohesión social y territorial y de desarrollo económico equilibrado, como ha sucedido en Europa, naturalmente teniendo en cuenta las significativas diferencias y evitando mimetismos jurídicos artificiales.

En línea con ello, y para cerrar este punto, coincidimos con Stähli respecto de las tres cuestiones centrales que plantea acerca de la existencia de una política regional en el marco de un esquema de integración, las que tienen que ver con los objetivos generales perseguidos: la democratización del proceso integrador, la incorporación a éste de una nueva dinámica y la corrección de los desequilibrios $^{62}$.

\section{La actividad internacional de las provincias}

A) Nótese que el multicitado art. 124 de la Carta fundamental prevé que las provincias "podrán también celebrar convenios internacionales en tanto no sean incompatibles con la política exterior de la Nación y no afecten las facultades delegadas al Gobierno federal o al crédito público de la Nación; con conocimiento del Congreso nacional».

La cuestión ha suscitado numerosas dudas en la doctrina, tanto en torno al grado de legitimación de las provincias para actuar internacionalmente y al alcance de tal eventual actividad, como al calibre semántico de la expresión «con conocimiento del Congreso nacional».

La problemática recepta importancia no sólo desde el plano especulativo o académico, sino primordialmente desde la óptica del refuerzo del federalismo, la revalorización de las gestiones que en el ámbito internacional les es lícito desplegar a las unidades provinciales y el rol que pueden jugar en el terreno de la integración supranacional, naturalmente dentro de los límites establecidos por la Ley fundamental, lo que supone dejar a buen resguardo el principio jurídicoaxiológico de lealtad constitucional que, justo es reiterar, no solamente vincula a las entidades infraestatales respecto del gobierno central, sino que, en retroalimentación, también compromete a éste con relación a aquéllas.

B) Un enfoque exegético del segmento del precepto constitucional citado lleva en primer término a puntualizar desde una dimensión genérica que tales actividades de alcance internacional o gestiones internacionales de las provincias, resul-

62 STÄHLI, J., «Participación de las regiones internas de los Estados en los procesos de integración», en un texto inédito que el autor tuviera la gentileza de enviarnos. 
tan legitimadas a partir de una percepción flexible de las «relaciones internacionales», cuya conducción y responsabilidad — como es de sobra conocidorecaen exclusivamente en el Estado federal en cuanto a lo que corporizaría el «núcleo duro» de aquellas relaciones.

Correlativamente, la mencionada laxitud interpretativa de dicha expresión permitiría pensar en un «núcleo blando» que habilita la realización de actividades de tenor internacional por parte de los entes subestatales, o lo que por ejemplo y mutatis mutandi, la doctrina italiana denomina «attività promozionali» («actividades de promoción exterior»), encaminadas justamente al fomento del desarrollo económico, social y cultural que las regiones pueden desempeñar con acuerdo del Gobierno ${ }^{63}$ (en el caso argentino, las provincias lo deben hacer «con conocimiento del Congreso nacional»).

Dicho en palabras de Casanovas y La Rosa, al margen de las «relaciones internacionales» en sentido estricto y de la celebración de tratados internacionales, cabe «articular un ámbito de acción exterior que se fundamente en los poderes e intereses propios de las entidades infraestatales y se ajuste a lo que es la práctica constitucional e internacional actual en los Estados de estructura compleja» ${ }^{64}$.

Aclarado lo anterior, y retomando en particular el tramo del art. 124 referido a las actividades que ad extra están facultadas a llevar adelante las provincias, la terminología «convenios internacionales» que pueden celebrar, suponemos ha sido pensada para transmitir un mensaje que exteriorice una distinción categorial enraizada en una valencia jurídica más tenue y menos formal que la de «tratados internacionales», que quedan inmersos —estos últimos— en la órbita competencial exclusiva del Estado nacional en el manejo de las relaciones internacionales ${ }^{65}$ («núcleo duro»).

63 AGOSTINI, M. V., «Líneas de evolución de la acción de las regiones italianas en el exterior y de su participación en el proceso de adopción de decisiones comunitarias», en AA. VV., La acción exterior y comunitaria de los Länder, regiones, cantones y comunidades autónomas, Vol. I, Bilbao, Universidad Carlos III de Madrid y Universidad del País Vasco, Instituto Vasco de Administración Pública, 1994, p. 24.

${ }^{64}$ CASANOVAS Y LA ROSA, O., «La acción exterior de las Comunidades Autónomas y su participación en la celebración de tratados internacionales», loc. cit. en nota anterior, pp. 57/58.

65 En general hay consenso doctrinario acerca de que, en el contexto de nuestra Ley Fundamental e interpretando la voluntad del constituyente reformador, la expresión «convenios internacionales» representa un escalón jerárquico inferior a la de «tratados internacionales», reservados al Estado nacional (Poderes ejecutivo y legislativo) en el marco de una fórmula léxica empleada por ejemplo en los arts. 27, 31 y 75, incs. 22, 23 y 24.

Sin embargo, es preciso recordar que desde un plano genérico y en el ámbito del derecho internacional, entre ambas denominaciones existen lazos de afinidad semántica. Es que la Conven- 
Justamente, la celebración de «convenios internacionales» por las unidades provinciales está supeditada a la compatibilidad «con la política exterior de la Nación» y la no afectación de «las facultades delegadas al Gobierno federal o al crédito público de la Nación». Puede acordarse o no con los lineamentos léxicos adoptados por el constituyente reformador de 1994 para trazar los límites a las actividades provinciales de alcance internacional, mas lo que sí queda claro es que en tal diseño lingüístico se inserta la matriz del citado principio de «lealtad constitucional», que en el particular las provincias deben acatar para preservar la intangibilidad del reparto de competencias acordado con el Estado nacional.

En definitiva, y en lo que hace al objeto de tales «convenios internacionales», parece claro que el mismo debe girar en torno a competencias exclusivas de las provincias o concurrentes con la Nación.

C) Por su parte, no menor polémica trae consigo la fórmula escogida en punto a que tanto la creación de regiones como la celebración de convenios internacionales deben realizarse «con conocimiento del Congreso nacional».

Liminarmente, nos apresuramos a aclarar que, desde nuestra óptica, «conocimiento» no origina la exigencia de consentimiento, aprobación ni autorización, sino de comunicación al Poder Legislativo.

ción de Viena sobre el Derecho de los Tratados (CVDT), de 23 de mayo de 1969, que entrara en vigor el 27 de enero de 1980, ha determinado que a los efectos de tal Convención, «se entiende por "tratado" un acuerdo internacional celebrado por escrito entre Estados y regido por el derecho internacional, ya conste en un instrumento único o en dos o más instrumentos conexos y cualquiera que sea su denominación particular» (cfr. art. 2.1.«a»).

Al explicar la citada definición, DE LA GUARDIA puntualiza que según tal Convención y a los efectos de su texto, «todo convenio será un "tratado" siempre que: a) sea un acuerdo internacional; b) haya sido celebrado por escrito; c) se haya concluido entre Estados; d) esté regido por el derecho internacional, y e) cualquiera sea su denominación particular y aunque conste en un instrumento único o en dos o más instrumentos conexos» (DE LA GUARDIA, E., Derecho de los tratados internacionales, Buenos Aires, Ábaco, 1997, p. 107). Justamente al desarrollar este último elemento de la definición, es decir, «cualquiera sea su denominación particular y aunque conste en un instrumento único o en dos o más instrumentos conexos», el citado autor recuerda que la Convención adhiere al criterio contemporáneo y generalizado en cuanto a la utilización del término «tratado», que abarca a «todos los acuerdos internacionales, sobre los que existe una gran variedad de denominaciones, como convención, protocolo, arreglo, declaración, carta, pacto, convenio, acta, acuerdo, estatuto, concordato, canje de notas, notas reversales, minutas aprobadas, memorándum de acuerdo, modus vivendi, etcétera» (ibíd., pp. 114/115).

Por su parte, en el ámbito del derecho comparado latinoamericano existen Constituciones que plasman en sus textos las nomenclaturas «tratados o convenios internacionales», por ejemplo, las de Bolivia (aprobada por referéndum en 2009) y Ecuador (sancionada en 2008). 
Tal posición reconoce varios puntos de sustentación: en primer lugar, por cuanto desde el ángulo semántico «con conocimiento» sólo supone el resultado de «hacer saber» $\mathrm{o}$ «informar», lo que dista conceptualmente de «consentimiento», «aprobación» u otros términos equivalentes; en segundo lugar, porque durante los trabajos y debates de la Convención Constituyente se manejaron varias opciones terminológicas para la redacción de este tramo de la norma, entre los que se cuentan los mencionados en último término, decantándose finalmente por la expresión «con conocimiento», que — reiteramos- exhibe una carga de significado distinta de las enunciadas, además de que no cabe predicar de los constituyentes una actuación desprevenida o inopinada en la selección del texto particular; y, por último, refuerza nuestra percepción el distanciamiento que en el punto se da en relación con la Constitución de EE. UU., una de las fuentes de la Ley fundamental argentina, que exige el «consentimiento» del Congreso para que el Estado celebre convenio o pacto alguno con otro Estado o con una potencia extranjera ${ }^{66}$ (art. I, Sección X, ap. 3).

Cuestión delicada es prefigurar qué sucedería en caso de que el Congreso estuviera en disconformidad con el acuerdo regional o que el convenio internacional violara los límites impuestos constitucionalmente. En tales hipótesis, y siempre que las vías previas del diálogo democrático fracasaren, cabría al Estado nacional la articulación de una acción judicial ante la CSJN en contra de las provincias (o la CABA) actuantes o, en un supuesto extremo y si eventualmente quedaran reunidas las pautas diseñadas por el art. 6 de la C. N., disponer la intervención federal (arts. 75, inc. 31, ó 99, inc. 20, ibíd.), en cuyo caso, Gelli sugiere que los senadores representantes de las provincias en cuestión o de la CABA, deberían defender «las razones y justificación de los Estados locales» —énfasis del original— ${ }^{67}$.

Advierte Hernández ${ }^{68}$ que un pronunciamiento negativo del Congreso no dejaría sin efecto el acuerdo, como sería el caso de la desaprobación.

Finalmente, y para aventar posibles cuestionamientos en el despliegue de la acción exterior de las provincias, Zarza Mensaque ofrece como alternativa que por medio de un acuerdo previo entre el Estado federal y aquéllas, «el Congreso

${ }^{66}$ La norma en cuestión, refiriéndose al ap. 2 del mismo artículo, expresa que sin el «consentimiento» del Congreso «ningún Estado podrá (...) celebrar convenio o pacto alguno con otro Estado o con una potencia extranjera,...» (el texto en español ha sido tomado de CASCAJO CASTRO, J. L. y GARCÍA ÁLVAREZ, M. [eds.], Constituciones extranjeras contemporáneas, 3. a ed., Madrid, Tecnos, 1994, p. 68).

${ }_{67}^{6}$ GELLI, M. A., Constitución de la Nación Argentina comentada y concordada, cit., p. 863.

68 HERNÁNDEZ, A. M., Integración y globalización: rol de las regiones, provincias y municipios, cit., p. 44. 
dicte una ley convenio que establezca los aspectos sustanciales y procedimentales que deben respetar los Estados locales para que los convenios que suscriban sean válidos» ${ }^{69}$.

5. ¿Son incompatibles los procesos de integración regional con el federalismo u otra forma de estructura estadual compleja? ${ }^{70}$

A) Nada se descubre al recordar que la irrupción de nuevos espacios integrados plantea, correlativamente, renovados desafíos, fundamentalmente en los esquemas estaduales de estructura territorial compleja. De su lado, cabe reiterar que el federalismo es un proceso dinámico y con numerosas fórmulas posibles de configuración.

Reproducimos el núcleo del interrogante que se dispara desde el epígrafe: ¿Existe incompatibilidad entre el establecimiento de bloques supranacionales (por ejemplo, ante una futura intensificación del ligamen subyacente en el Mercosur —instituida por el Tratado de Asunción ${ }^{71}$-), que supone un movimiento de centralización, y el federalismo intraestatal, que por vía de principio (y no sin ciertas matizaciones) contiene una nota de descentralización política?

La respuesta es, a nuestro criterio, negativa. No cabría predicar a priori semejante contradicción. Antes bien, lo deseable sería generar una saludable relación

69 ZARZA MENSAQUE, A., «Las provincias en las relaciones interjurisdiccionales», en DRNAS DE CLÉMENT, Z. y REY CARO, E. J. (dirs.), Jornadas de reflexión sobre regionalización y Mercosur, Córdoba (Argentina), Marcos Lerner Editora, 2000, p. 59.

70 Ver para ampliar, BAZÁN, V., «La integración supranacional y el federalismo en interacción: perspectivas y desafíos», Boletín Mexicano de Derecho Comparado, No 124, Nueva Serie, Año XLII, enero-abril 2009, México D. F., IIJ, UNAM, pp. 59/124.

${ }^{71}$ El Tratado de Asunción fue suscrito el 26 de marzo de 1991 por la República Argentina, la República Federativa de Brasil, la República del Paraguay y la República Oriental del Uruguay.

En 2004 Venezuela comenzó a transitar su camino en el Mercosur por medio del Acuerdo de Complementación Económica Mercosur - Colombia, Ecuador y Venezuela.

Por su parte, el 4 de julio de 2006 se suscribió en Caracas el Protocolo de Adhesión de la República Bolivariana de Venezuela al Mercosur, y más recientemente, el 31 de julio de 2012 - en el marco de una cumbre extraordinaria celebrada en Brasilia por los presidentes de la Argentina, Brasil y Uruguay, y sin la presencia de Paraguay, por estar suspendido- Venezuela ha pasado a conformar el Mercosur como miembro pleno.

En torno a ésta y otras cuestiones relativas al Mercosur, ver BAZÁN, V., «Mercosur y derechos humanos: panorama, problemas y desafíos», en VON BOGDANDY, A., PIOVESAN, F. y MORALES ANTONIAZZI, M. (eds.), Direitos bumanos, Democracia e Integração Jurídica: avançando no diálogo constitucional e regional, Max-Planck-Institut für ausländisches öffentliches Recht und Völkerrecht, Pontifícia Universidade Católica de São Paulo, Rio de Janeiro, Lumen Juris, 2011, pp. $473 / 529$. 
de complementación entre integración (estructura comunitaria) y autonomía (federalismo u otros procesos de desconcentración política), a partir de claras normas contenidas en la Ley fundamental de que se trate, que permitan al Estado nacional involucrarse en procesos integrativos preservando la pluralidad y las pautas de descentralización ad intra ${ }^{72}$.

B) Mutatis mutandi, Rolla puntualiza que «el derecho comparado muestra cómo el empuje de la descentralización no alimenta las tendencias centrífugas o particularistas en las experiencias donde el sistema constitucional es capaz de identificar y codificar los valores en torno a los cuales todos los sujetos del pluralismo se reconocen» ${ }^{73}$.

El problema no es precisamente reciente. Por el contrario, con frecuencia cobra renovado impulso ya que aparecen cuestiones conflictivas nuevas o se reinventan aristas de otras que parecían ya solventadas y superadas.

Entre un cúmulo de aspectos relevantes de la cuestión y, por cierto, controversiales, pueden destacarse ejemplificativamente dos: por una parte, el impacto que la integración puede provocar en las regiones, provincias, comunidades autónomas, etc.; y, por otra, el modo en que estos entes podrían participar en los procesos de decisión de la estructura comunitaria, tema catalogado como «ineludible» por el autor citado en último término, quien añade que tal problemática necesita de procedimientos adecuados de colaboración entre los diversos niveles institucionales que componen el ordenamiento nacional ${ }^{74}$.

En el ámbito interno argentino, la plataforma legitimante de tal relación de colaboración es un esquema de federalismo de concertación, que permita una vinculación equilibrada entre las instancias que forman la estructura federal y viabilice una alternativa de desarrollo y crecimiento integrado ad intra y ad extra.

Paralelamente, tal paradigma equilibrado deberá trasladarse al sistema comunitario y su cuadro de distribución y ejercicio de competencias con cada uno de los Estados Miembros, respetando las pautas de atribución, subsidiariedad, proporcionalidad y necesidad.

${ }^{72}$ La cuestión nos interesa y preocupa desde hace bastante tiempo, incluso antes de la reforma constitucional de 1994. Al respecto, ver BAZÁN, V., «Las provincias desde la perspectiva de la integración regional», en BAZÁN, V. et al. (comps.), Integración regional: Perspectivas para Latinoamérica, San Juan (Argentina), Edit. Fundación Universitaria, 1994, pp. 205/218.

73 ROLLA, Giancarlo, «La descentralización en Italia. Un difícil equilibrio entre autonomía y unidad», en HERNÁNDEZ, A. M. (dir.), La descentralización del poder en el Estado contemporáneo, Córdoba (Argentina), Asociación Argentina de Derecho Constitucional, Instituto Italiano de Cultura de Córdoba e Instituto de Derecho Constitucional y Derecho Público Provincial y Municipal de la Facultad de Derecho y Ciencias Sociales de la Universidad Nacional de Córdoba, 2005, p. 44.

74 Ibíd., p. 42. 
A propósito de todo ello, en la praxis comunitaria europea - que, como anticipábamos, pese a las claras diferencias con el Mercosur es el contexto del que se debe abrevar para extraer algunas enseñanzas que quizá resulten prospectivamente extrapolables, no sin beneficio de inventario, a nuestro modelo integrativo_- se ha reclamado la necesidad de dar coherencia a la participación regional en el proceso de integración, por medio de la institucionalización de un diálogo en dos frentes: el comunitario, permitiendo a las regiones comunicarse con las instituciones de la Unión Europea $\left(\mathrm{UE}^{75}\right)$; y el interno del Estado, suscitando una colaboración entre las autoridades centrales y las autoridades regionales en relación con dicho proceso $^{76}$.

Naturalmente la cuestión se comprende a partir del resultado de lo que, como vimos, se ha explicado como la reconducción del concepto clásico de "política exterior», separando el «núcleo duro» (cuya diagramación compete al Estado), de un conjunto de acciones que giran en su derredor, de «relieve internacional» o de "promoción exterior», consecuencia del proceso de globalización o internacionalización, y cuya realización puede y debe ser llevada a cabo por las entidades subestatales bajo el principio liminar de la «lealtad constitucional» ${ }^{77}$.

\section{APORTACIONES COMPLEMENTARIAS}

No deseábamos finalizar este trabajo sin añadir unas líneas sobre algunas cuestiones de interés vinculadas a los derechos fundamentales, los mecanismos procesal-constitucionales para operativizarlos y otros puntos significativos asociados a los compromisos convencionales asumidos internacionalmente por el Estado nacional en el marco de los derechos humanos.

\section{El derecho público provincial y sus reflejos anticipatorios vis-à-vis la Constitución nacional}

Es de destacar la importancia anticipatoria que frente a la C. N. exhibe el constitucionalismo provincial argentino, cuyo ciclo reformador comenzado en épocas cronológicamente próximas a la finalización de la aciaga dictadura mili-

$75 \mathrm{Al}$ respecto, debe tenerse en cuenta el Tratado de Lisboa (Diario Oficial de la Unión Europea, 17 de diciembre de 2007), que entró en vigor el 1 de diciembre de 2009.

${ }^{76}$ Cfr. PÉREZ GONZÁLEZ, M., «Facultades de los entes subnacionales en el sistema comunitario europeo», en DRNAS DE CLÉMENT, Z. y REY CARO, E. J. (dirs.), Jornadas de reflexión sobre regionalización y Mercosur, cit., pp. 18/19.

77 Cfr., mutatis mutandi, LEGUINA, J., «Intervención de apertura», en La acción exterior y comunitaria de los Länder, regiones, cantones y comunidades autónomas, cit., p. 16. 
tar iniciada en 1976 y concluida con la histórica recuperación democrática de fines de 1983, fue deparando múltiples instituciones, varias de las cuales recién quedaron receptadas por la Carta federal mediante la innovación constitucional de 1994.

En esa línea se presentan numerosos derechos y procesos constitucionales que recién fueron literalizados en la Ley fundamental nacional en la última innovación constitucional pero que ya llevaban bastante tiempo positivados en diversas constituciones provinciales. Por ejemplo, en materia de importantes derechos como los relativos al consumidor y al medio ambiente; y los procesos constitucionales de amparo y hábeas data.

Otro tanto ocurrió, como tuvimos ocasión de verificar supra, con la consagración en diversas constituciones provinciales de la autonomía municipal a partir de 1957 y con mayor contundencia en el ciclo constituyente reformador comenzado en 1985, proceso de normatización similar al que aconteció con la preceptiva referente a los recursos naturales.

\section{En materia de derechos humanos, la Constitución nacional ¿es un piso o un tope para las constituciones provinciales?}

Específicamente en el campo de los derechos y garantías constitucionales, es muy importante tener en cuenta que la C. N. marca un umbral, una plataforma básica protectoria, que puede ser ampliada (y de hecho así ha sido) en sus respectivos marcos competenciales por las leyes fundamentales provinciales. En otras palabras, la Carta magna nacional es un piso y no un tope máximo.

Aquella atribución surge, inter alia, del carácter autonómico que las provincias ostentan en el plano federal y siempre que sea ejercida dentro de los límites de sus jurisdicciones sobre la base del reparto competencial diseñado por la C. N.

Como es obvio suponer, las constituciones provinciales no deberían establecer normas que fuesen contrarias a la Constitución federal pues, de hacerlo, las mismas serían pasibles de ser declaradas inconstitucionales. Es que la Constitución federal impone, como adelantábamos, un mínimo de derechos «con rígido carácter de canon indisponible» ${ }^{78}$, que prohíbe su disminución como también veda la reducción del contenido esencial de los mismos.

Por tanto, si bien es cierto que las provincias pueden amplificar el bloque mínimo federal de derechos (construido por los consagrados - e implícitos-en la Carta magna, los instrumentos internacionales sobre derechos humanos con

${ }^{78}$ BIDART CAMPOS, G. J., Tratado elemental de derecho constitucional argentino, $\mathrm{T}^{\mathrm{o}} \mathrm{V}$, Buenos Aires, Ediar, 1994, p. 166. 
jerarquía constitucional ${ }^{79}$ o las leyes nacionales), dotándolo de mayor o mejor contenido o añadiendo otros derechos, tales optimizaciones sólo tendrían cabida — como señala Bidart Campos_ en tanto fuesen oponibles a la misma provincia que las dispusiera y/o a los particulares como sujetos pasivos gravados con una obligación, pero nunca para convertir al Estado federal en sujeto pasivo con deberes que excedieran los que a él imponga la C. N. ${ }^{80}$

\section{Sobre la denominada "cláusula federal» 81}

A) Otro punto de interés que involucra al federalismo (y a otras formas de vertebración estatal compleja) es la denominada cláusula federal prevista en la

79 En cuanto al rango de los instrumentos internacionales en la órbita normativa interna argentina, se ha dado un importante paso, pues la reforma constitucional de 1994 les ha adjudicado en general una jerarquía superior a la de las leyes nacionales —art. 75, incs. 22, párr. $1^{\circ}$ - al tiempo de haber acordado jerarquía constitucional a once instrumentos internacionales sobre derechos humanos (enumerados en el art. 75 , inc. 22 , párr. $2^{\circ}$ ) y a los que en el futuro se les acuerde tal valencia (párr. $3^{\circ}$ de dicho inciso).

Por tanto, podría decirse que existen instrumentos internacionales relativos a derechos humanos que ostentan jerarquía constitucional originaria y otros que receptan jerarquía constitucional derivada.

Entre los primeros, es decir, los enumerados específicamente por la Ley fundamental, se encuentran: la Declaración Americana de los Derechos y Deberes del Hombre; la Declaración Universal de Derechos Humanos; la Convención Americana sobre Derechos Humanos (CADH); el Pacto Internacional de Derechos Económicos, Sociales y Culturales; el Pacto Internacional de Derechos Civiles y Políticos y su Protocolo Facultativo; la Convención sobre la Prevención y la Sanción del Delito de Genocidio; la Convención Internacional sobre la Eliminación de todas las Formas de Discriminación Racial; la Convención sobre la Eliminación de todas las Formas de Discriminación contra la Mujer; la Convención contra la Tortura y otros Tratos o Penas Crueles, Inbumanos o Degradantes; y la Convención sobre los Derechos del Niño.

Ya en la segunda modalidad procedimental, esto es, los ungidos con valencia constitucional expost, se cuentan la Convención Interamericana sobre Desaparición Forzada de Personas, consagrada por la 24. ${ }^{a}$ Asamblea General de la OEA, celebrada el 9 de junio de 1994 en Belem do Pará, Brasil, y a la que se le dispensó tal cotización constitucional por conducto de la Ley $\mathrm{N}^{\circ} 24.820$, publicada el 29 de mayo de 1997; y la Convención sobre la Imprescriptibilidad de los Crímenes de Guerra y de los Crímenes de Lesa Humanidad, a la que se ha conferido esa valía mediante la Ley $\mathrm{N}^{\circ} 25.778$, publicada el 3 de setiembre de 2003.

${ }^{80}$ BIDART CAMPOS, G. J., Tratado elemental de derecho constitucional argentino, $\mathrm{T}^{\circ} \mathrm{V}$, cit., pp. $166 / 167$.

${ }^{81}$ En el texto nos ceñiremos a la «cláusula federal» contenida por ejemplo en el art. 28 de la $\mathrm{CADH}$ y otros instrumentos internacionales en el campo de los derechos fundamentales.

La aclaración obedece a que, por inspiración del autor Pedro J. Frías, se insertaron «cláusulas federales» en varias cartas básicas provinciales sancionadas con posterioridad a 1985.

Según afirma Bidart Campos, la «cláusula federal», girando sobre el eje de la relación de subordinación bien interpretada, intenta redefinir desde un federalismo de concertación el reparto 
Convención Americana sobre Derechos Humanos (CADH), entre otros instrumentos, por ejemplo, la Convención sobre los Derechos de las Personas con Discapacidad.

En el caso de la CADH dicha cláusula «impone al gobierno nacional el cumplimiento de todas las obligaciones relacionadas con las materias sobre las que ejerce jurisdicción legislativa y judicial, y el deber de tomar "de inmediato" las medidas pertinentes, conforme a su constitución y sus leyes, para que las autoridades componentes del Estado federal puedan cumplir con las disposiciones de ese tratado» (art. 28 , incs. $1^{\circ}$ y $2^{\circ}$ ).

Ello, aun cuando tal disposición de la CADH haya sido calificada por prestigiosa doctrina como un «anacronismo» ${ }^{82}$, desde que no se enrola en la línea descripta por los tratados internacionales que no incorporan tal cláusula federal, ya que - por caso - la misma no consta en el Pacto Internacional de Derechos Civiles y Políticos ${ }^{83}$ ni en la Convención Europea sobre Derechos Humanos y Libertades Fundamentales.

Buergenthal recuerda que la nombrada premisa se remonta a la era de la Sociedad de las Naciones y que fue incluida en la CADH por insistencia de EE. UU., cuya delegación propuso tal artículo para garantizar que no se considere a un Estado federal como asumiendo obligaciones internacionales para impedir violaciones a la Convención con respecto a derechos o actos de la jurisdicción de una entidad gubernamental que no sea el gobierno federal; además de que, al limitar las obligaciones internacionales del Estado federal a materias sobre las cuales ejerce su jurisdicción, EE. UU. quería indicar que tal Estado no tiene, según la Convención, ninguna obligación en aquellas situaciones en las cuales el gobierno federal, aun cuando tenga jurisdicción, no la haya ejercido anteriormente $^{84}$

Fuera de algunos ingredientes históricos y políticos que figuran en el ADN de dicha pauta normativa, no está de más reiterar que, al interpretarla — estan-

competencial dentro del marco trazado por la Constitución federal. Para este último autor tal cláusula es «una expresión provincial que afianza un diseño federal ortodoxo y que, desde las provincias, alcanza la jerarquía de la Constitución local para tratar de imprimir un nuevo sesgo a las relaciones interjurisdiccionales, tanto como recuperar competencias perdidas, avasalladas o, por lo menos, perturbadas en disfavor de las autonomías locales...» (BIDART CAMPOS, G. J., «La cláusula federal en el constitucionalismo provincial», Tratado elemental de derecho constitucional argentino, $\mathrm{T}^{\circ} \mathrm{V}$, cit., pp. 185/186).

82 BUERGENTHAL, T., «La cláusula federal de la Convención Americana», en BUERGENTHAL, T., NORRIS, R. E. y SHELTON, D., La protección de los derechos humanos en las Américas, 1. a ed., reimpres., Madrid, Instituto Interamericano de Derechos Humanos - Civitas, 1994, p. 85.

${ }^{83}$ Que en su art. 50 justamente entroniza el principio opuesto a la cláusula federal.

84 BUERGENTHAL, T., «La cláusula federal de la Convención Americana», cit., pp. 85/86. 
do contenida como se dijo en un tratado internacional - deben tenerse en consideración los principios generales del derecho internacional y la jurisprudencia y la práctica internacionales en este campo. Ciertamente, tal cuestión apunta a afianzar la efectividad de los instrumentos de derechos humanos en el plano del derecho interno estatal, efectividad que resulta de la propia naturaleza jurídica de aquéllos, a lo que se debe agregar el imperativo ético y la necesidad de que los Estados compatibilicen su normativa y sentencias a las decisiones de los tribunales internacionales ${ }^{85}$.

B) Aunque parezca una cuestión superada o sólo de interés especulativo o académico, lo que parece obvio no es siempre ni en todos los lugares, tan obvio. Si no, basta con repasar los párrs. 45 y 46 de la sentencia de reparaciones y costas dictada por la Corte Interamericana de Derechos Humanos (Corte IDH) en el «Caso Garrido y Baigorria vs. Argentina», que pasamos a transcribir ${ }^{86}$ :

«La Comisión solicitó a la Corte que se pronuncie acerca de la cláusula federal (artículo 28 de la Convención Americana) y del alcance de las obligaciones del Estado argentino en la etapa de reparaciones, en relación con dicha cláusula (...). La Argentina invocó la cláusula federal o hizo referencia a la estructura federal del Estado en tres momentos de esta controversia. En primer lugar, cuando se discutía el fondo del asunto, el Estado sostuvo que la responsabilidad del caso no recaía sobre él, sino en la provincia de Mendoza, en virtud de la cláusula federal. La Argentina desistió luego de este planteamiento y reconoció expresamente su responsabilidad internacional en la audiencia de 1 de febrero de 1996 (...). El Estado pretendió por segunda vez hacer valer la cláusula federal al concertarse el convenio sobre reparaciones de 31 de mayo de 1996. En esa oportunidad, apareció como parte en el convenio la provincia de Mendoza y no la República Argentina, pese a que esta última ya había reconocido su responsabilidad internacional. La Corte decidió entonces que dicho convenio no era un acuerdo entre partes por no haber sido suscrito por la República Argentina, que es la parte en esta controversia (...). Por último, en la audiencia de 20 de enero de 1998 la Argentina alegó haber tenido dificultades para adoptar ciertas medidas debido a la estructura federal del Estado...»

«El artículo 28 de la Convención prevé la hipótesis de que un Estado federal, en el cual la competencia en materia de derechos humanos corresponde a los Estados miembros, quiera ser parte en ella. $\mathrm{Al}$ respecto, dado que desde el momento de la aprobación y de la ratificación de la Convención la Argentina se comportó como si dicha competencia en materia de derechos humanos corres-

${ }^{85}$ Ver para ampliar, CANÇADO TRINDADE, A. A., El derecho internacional de los derechos bumanos en el siglo XXI, Santiago, Editorial Jurídica de Chile, 2001, pp. 380 y ss.

${ }^{86}$ Corte IDH, «Caso Garrido y Baigorria vs. Argentina», Sentencia de Reparaciones y Costas, 27 de agosto de 1998, Serie C, No 39, párrs. 45 y 46. 
pondiera al Estado federal, no puede ahora alegar lo contrario pues ello implicaría violar la regla del estoppel. En cuanto a las "dificultades" invocadas por el Estado en la audiencia de 20 de enero de 1998, la Corte estima conveniente recordar que, según una jurisprudencia centenaria y que no ha variado hasta abora, un Estado no puede alegar su estructura federal para dejar de cumplir una obligación internacional (Cfr.: sentencia arbitral de 26. VII.1875 en el caso del Montijo, La PradellePolitis, Recueil des arbitrages internationaux, Paris, 1954, t. III, p. 675; decisión de la Comisión de reclamaciones franco-mexicana del 7. VI.1929 en el caso de la sucesión de Hyacinthe Pellat, U. N., Reports of International Arbitral Awards, vol. V, p. 536)»—énfasis añadido—.

Si bien huelgan mayores comentarios en torno a la inviabilidad estatal de alegar normativa, insuficiencias o inconvenientes de su derecho interno para incumplir las obligaciones impuestas por la Corte IDH, sólo evocaremos aquí la necesidad de leer conjuntamente los arts. 1.1, 2 y 28 de la CADH para dar cumplimiento a aquellas directivas jurisdiccionales, pues — como afirma Dulitzkytal art. 28 «tiene por objeto clarificar, precisar y hacer más determinante, inmediata y directa la exigencia del cumplimento de la obligación de respetar y garantizar los derechos y libertades en el marco de los Estados federales», añadiendo que dicha norma «no altera o disminuye el alcance de los arts. 1 y 2 de la Convención sino que los complementa. Una interpretación distinta, carecería de sentido al privar de efecto útil a la Convención en las unidades componentes de los Estados federales» ${ }^{87}$.

Acerca de este último aspecto, la Corte IDH ha expresado - mutatis mutandi - la necesidad de velar por el efecto útil de los instrumentos internacionales, de manera que no quede mermado o anulado por la aplicación de normas o prácticas internas contrarias al objeto y fin del instrumento internacional o del estándar internacional de protección de los derechos humanos ${ }^{88}$.

Sería desatinado obviar como material de análisis para ponderar debidamente la cuestión, el deber de honrar los compromisos asumidos internacionalmen-

${ }^{87}$ DULITZKY, A. E., «La Convención Americana sobre Derechos Humanos y los Estados federales: algunas reflexiones», en BAZÁN, V. (coord.), Defensa de la Constitución. Garantismo y controles. Libro en reconocimiento al Doctor Germán J. Bidart Campos, Buenos Aires, Ediar, 2003, p. 172.

${ }^{88}$ Cfr. v. gr., Corte IDH, «Caso Heliodoro Portugal vs. Panamá», Sentencia de Excepciones Preliminares, Fondo, Reparaciones y Costas, 12 de agosto de 2008, Serie C, No 186, párr. 180; «Caso Almonacid Arellano y otros vs. Chile», Sentencia de Excepciones Preliminares, Fondo, Reparaciones y Costas, 26 de septiembre de 2006, Serie C, No 154, párr. 124; «Caso Trabajadores Cesados del Congreso (Aguado Alfaro y otros) vs. Perú», Sentencia de Excepciones Preliminares, Fondo, Reparaciones y Costas, 24 de noviembre de 2006, Serie C, No 158, párr. 128; y «Caso Boyce y otros vs. Barbados», Sentencia de Excepción Preliminar, Fondo, Reparaciones y Costas, 20 de noviembre de 2007, Serie C, No 169, párr. 113. 
te y el debido respeto que demandan los principios generales del derecho. En particular, las exigencias de las pautas pacta sunt servanda (premisa fundamental, de raigambre metajurídica ${ }^{89}$, del derecho de los tratados internacionales); cumplimiento de buena fe (que recorre transversalmente a todo el derecho internacional), e improcedencia de alegar disposiciones (u omisiones — según nuestro criterio-) de derecho interno para justificar el incumplimiento de los convenios internacionales ${ }^{90}$.

Todo ello de acuerdo, en lo respectivamente correspondiente, con los arts. 26, 31.1 y 27 (este último con la excepción contenida en el art. 46) de la citada Convención de Viena (CVDT), de 23 de mayo de $1969^{91}$, conjunto de reglas medulares en materia de observancia de los instrumentos internacionales convencionales ${ }^{92}$.

C) En suma, una interpretación amplia y dinámica de la «cláusula federal» lleva a pensar, por un lado, que ad intra la protección que prefigura el documento internacional en cuestión debe ser equivalente para los habitantes en los

$89 \mathrm{Al}$ respecto, y en su voto disidente en el «Caso Caballero Delgado y Santana vs. Colombia» (Sentencia de Reparaciones y Costas, 29 de enero de 1997, Serie C, No 31, párr. 8), el ex presidente del Tribunal Interamericano dejó en claro que el principio general pacta sunt servanda tiene fuente metajurídica, «al buscar basarse, mas allá del consentimiento individual de cada Estado, en consideraciones acerca del carácter obligatorio de los deberes derivados de los tratados internacionales».

90 Sólo por traer aquí una cita ejemplificativa, evocamos que la Corte IDH ha sostenido: «Según el derecho internacional las obligaciones que éste impone deben ser cumplidas de buena fe y no puede invocarse para su incumplimiento el derecho interno. Estas reglas pueden ser consideradas como principios generales del derecho y han sido aplicadas, aun tratándose de disposiciones de carácter constitucional, por la Corte Permanente de Justicia Internacional y la Corte Internacional de Justicia (...). Asimismo estas reglas han sido codificadas en los artículos 26 y 27 de la Convención de Viena sobre el Derecho de los Tratados de 1969» (cfr. Opinión Consultiva OC-14/94, «Responsabilidad internacional por expedición y aplicación de leyes violatorias de la Convención [arts. 1 y 2]», 9 de diciembre de 1994, solicitada por la Comisión Interamericana de Derechos Humanos [Comisión IDH], Serie A, No 14, párr. 35).

91 U. N. Doc A/CONF.39/27 (1969), 1155 U. N. T. S. 331.

92 En lo tocante al art. 26 de la CVDT, y su reflejo en el art. 31.1, ibíd., cabe resaltar que al enunciado tradicional en punto a que «los pactos deben ser cumplidos», la disposición añade «de buena fe», que naturalmente es un principio general del derecho.

Pero más allá de encontrarse en el cuerpo normativo de la Convención, tales premisas adquieren un refuerzo axiológico, anche jurídico, al haber quedado literalizadas también en el Preámbulo de la misma, que en su párr. $3^{\circ}$ reza: «Advirtiendo que los principios del libre consentimiento y de la buena fe y la norma pacta sunt servanda están universalmente reconocidos».

A su tiempo, entre los principios de la Organización de Naciones Unidas (ONU), su Carta establece en el art. 2.2. lo siguiente: «Los Miembros de la Organización, a fin de asegurarse los derechos y beneficios inherentes a su condición de tales, cumplirán de buena fe las obligaciones contraídas por ellos de conformidad con esta Carta» —énfasis añadido- (sobre tales tópicos, ver para ampliar DE LA GUARDIA, ERNESTO, Derecho de los tratados internacionales, cit., pp. 94/95). 
ámbitos de las distintas provincias que compongan cada Estado federal; y, por el otro, que a la luz del instrumento internacional de que se trate los pobladores de Estados federales no deberían ostentar un nivel tuitivo inferior al de los que habitan en Estados con estructura diversa (v. gr., unitario o centralizado).

Es preciso tener en cuenta que - como la Corte IDH ha sostenido insistentemente- los tratados modernos sobre derechos humanos tienen un carácter especial, cuyos objeto y fin confluyen en un punto común: la protección de los derechos fundamentales de los seres bumanos, con independencia de su nacionalidad, tanto frente a su propio Estado cuanto a los restantes Estados contratantes. Es decir, no son tratados multilaterales del tipo tradicional, concluidos en función de un intercambio recíproco de derechos, para el beneficio mutuo de los Estados contratantes; por el contrario, cuando los Estados aprueban un tratado sobre derechos humanos quedan sometidos a un ordenamiento legal dentro del cual asumen diversas obligaciones en relación con los individuos bajo su jurisdicción y no frente a otros Estados ${ }^{93}$.

Al hilo de ello, no sería legítimamente posible soslayar una directriz axiológicamente relevante: los derechos bumanos son la expresión directa de la dignidad de la persona bumana.

\section{El control de convencionalidad}

A) Ciertamente, el deber de pugnar por preservar el efecto útil de los instrumentos internacionales sobre derechos humanos y la improcedencia de alegar disposiciones u omisiones de derecho interno para soslayar el cumplimiento de obligaciones internacionales a los que nos referíamos líneas arriba, se vincula con la compleja cuestión del control de convencionalidad ${ }^{94}$, que si bien no podemos

93 Ver, por ejemplo, Corte IDH, Opinión Consultiva OC-2/82, «El efecto de las reservas sobre la entrada en vigencia de la Convención Americana sobre Derechos Humanos (arts. 74 y 75)», 24 de septiembre de 1982, solicitada por la Comisión IDH, Serie A, No 2, párr. 29.

Un análisis de tal opinión consultiva puede compulsarse en BAZÁN, V., «La Convención Americana sobre Derechos Humanos y el efecto de las reservas respecto de su entrada en vigencia: a propósito de la OC-2/82 de la Corte Interamericana de Derechos Humanos», en BIDART CAMPOS, G. J. et. al. (coords.), Derechos humanos. Corte Interamericana, Ediciones Jurídicas Cuyo, $\mathrm{T}^{\circ}$ I, Mendoza, 2000, pp. 91/165.

${ }^{94}$ En torno al tema, vid. BAZÁN, V., por ejemplo en «El control de convencionalidad: incógnitas, desafíos y perspectivas», BAZÁN, V. et. al. (eds.), Justicia Constitucional y Derechos Fundamentales. Control de Convencionalidad, Programa Estado de Derecho de la Fundación Konrad Adenauer y Centro de Derechos Humanos de la Facultad de Derecho de la Universidad de Chile, Bogotá, 2012, pp. 17/55; y «Control de convencionalidad, aperturas dialógicas e influencias jurisdiccionales recíprocas», Revista Europea de Derechos Fundamentales, No 18, $2^{\circ}$ Semestre 2011, 
desarrollar exhaustivamente aquí, merece que al menos le dediquemos unas breves líneas antes de pasar al cierre de este trabajo.

Tal contralor de convencionalidad transita por dos vertientes:

a) Una se desarrolla en sede internacional, y se deposita en el Tribunal Interamericano que ha venido desplegándola desde siempre en el marco de su jurisdicción contenciosa, aunque sólo en época reciente la ha denominado «control de convencionalidad».

b) La restante se desenvuelve en el contexto nacional, está a cargo de los magistrados locales y otras autoridades públicas ${ }^{95}$ (todos vinculados por la jurisprudencia interamericana) y enraíza en el deber que sobre ellos pesa en cuanto a constatar la compatibilidad de las reglas jurídicas internas que aplican en casos concretos con la CADH y otros instrumentos internacionales básicos en materia de derechos humanos respecto de los cuales la Corte IDH ejerce competencia ratione materiae, además de los patrones hermenéuticos que ésta ha elaborado en su faena jurisprudencial.

B) Procurando compendiar en la jurisprudencia de la Corte IDH la secuencia creciente de destinatarios involucrados en el deber de desplegar el control de convencionalidad en el ámbito interno y el crecimiento del alcance material de tal test de compatibilidad convencional, se observa que pueden identificarse hasta el momento los siguientes eslabones:

i) Poder Judicial ( Caso Almonacid Arellano y otros vs. Chile» ${ }^{96}$ ).

ii) Órganos del Poder Judicial («Caso Trabajadores Cesados del Congreso vs. Perú» $\left.{ }^{97}\right)$.

Fundación Profesor Manuel Broseta e Instituto de Derecho Público Universidad Rey Juan Carlos, Valencia, 2012, pp. 63/104.

95 Ver al respecto, entre otros pronunciamientos de la Corte IDH, el «Caso Gelman vs. Uruguay», Sentencia de Fondo y Reparaciones, 24 de febrero de 2011, Serie C, № 221.

En tal ocasión, sostuvo que «...particularmente en casos de graves violaciones a las normas del Derecho Internacional de los Derechos, la protección de los derechos humanos constituye un límite infranqueable a la regla de mayorías, es decir, a la esfera de lo "susceptible de ser decidido" por parte de las mayorías en instancias democráticas, en las cuales también debe primar un "control de convencionalidad" (...), que es función y tarea de cualquier autoridad pública y no sólo del Poder Judicial» —remarcado agregado- (párr. 239).

96 Corte IDH, «Caso Almonacid Arellano y otros vs. Chile», cit., párr. 124.

${ }^{97}$ Corte IDH, «Caso Trabajadores Cesados del Congreso (Aguado Alfaro y otros) vs. Perú», cit., párr. 128. 
iii) Jueces y órganos vinculados a la administración de justicia en todos los niveles ( Caso Cabrera García y Montiel Flores vs. México» ${ }^{98}$ ).

iv) Cualquier autoridad pública y no sólo el Poder Judicial («Caso Gelman vs. Uruguay» ${ }^{99}$ ).

v) Adecuación de las interpretaciones judiciales y administrativas y de las garantías judiciales a los principios establecidos en la jurisprudencia de la Corte IDH ( «Caso López Mendoza vs. Venezuela» ${ }^{100}$ y «Caso Atala Riffo y Niñas vs. Chile" $\left.{ }^{101}\right)$.

vi) «obligación propia de todo poder, órgano o autoridad del Estado Parte en la Convención, los cuales deben, en el marco de sus respectivas competencias y de las regulaciones procesales correspondientes, controlar que los derechos humanos de las personas sometidas a su jurisdicción sean respetados y garantizados», adquiriendo, así, «sentido el mecanismo convencional, el cual obliga a todos los jueces y órganos judiciales a prevenir potenciales violaciones a derechos bumanos, las cuales deben solucionarse a nivel interno teniendo en cuenta las interpretaciones de la Corte Interamericana y, sólo en caso contrario, pueden ser considerados por ésta, en cuyo supuesto ejercerá un control complementario de convencionalidad» —énfasis agregado- ( «Caso de la Masacre de Santo Domingo vs. Colombia» y «Caso Gelman vs. Uruguay», Resolución de 20 de marzo de 2013, Supervisión de cumplimiento de sentencia ${ }^{102}$ ).

C) La importancia del control de convencionalidad puede verificarse a partir de contemplar que la mayoría de los países que pertenecen al esquema interamericano han sido condenados por la Corte IDH a realizarlo. Además, ello se ha dado no sólo en pronunciamientos de fondo, reparaciones y costas, sino también en el marco de recursos de interpretación y en el ejercicio de facultades de supervisión de sentencias de dicho tribunal.

Como puede suponerse, la obligación de los jueces y demás autoridades públicas concernidas en punto a llevar adelante tal fiscalización de convenciona-

98 Corte IDH, «Caso Cabrera García y Montiel Flores vs. México», Sentencia de Excepción Preliminar, Fondo, Reparaciones y Costas, 26 de noviembre de 2010, Serie C, No 220, párr. 225.

99 Corte IDH, «Caso Gelman vs. Uruguay», cit., párr. 239.

100 Corte IDH, «Caso López Mendoza vs. Venezuela», Sentencia de Fondo, Reparaciones y Costas, 1 de septiembre de 2011, Serie C, No 233, párr. 228.

${ }^{101}$ Corte IDH, «Caso Atala Riffo y Niñas vs. Chile», Sentencia de Fondo, Reparaciones y Costas, 24 de febrero de 2012, Serie C, N 239, párr. 284.

${ }^{102}$ Corte IDH, «Caso de la Masacre de Santo Domingo vs. Colombia», Sentencia de Excepciones Preliminares, Fondo y Reparaciones, 30 de noviembre de 2012, Serie C, № 259, párr. 144; y «Caso Gelman vs. Uruguay», Supervisión de cumplimiento de sentencia, Resolución de 20 de marzo de 2013, párr. 72. 
lidad alcanza por igual a Estados unitarios y federales inmersos en el sistema interamericano.

Dicho de otro modo, el Estado federal en cuestión (Argentina, Brasil, México) no podría invocar su configuración estatal compuesta o compleja para preterir el cumplimiento de semejante deber internacional.

Antes de pasar a las valoraciones de cierre de este trabajo, y tal vez cuando pueda parecer sobreabundante, debe subrayarse que una conducta estatal contraria a lo indicado comprometería directamente la responsabilidad internacional del Estado de que se trate.

\section{EPÍLOGO}

1. El federalismo es un proceso dinámico y con numerosas fórmulas posibles de configuración, por lo que existen tantos federalismos como Estados federales con sus numerosas modalidades y variantes.

2. Hasta el presente, y tomando como punto de partida la reforma constitucional de 1994 que en su hora esgrimía como uno de sus objetivos centrales el fortalecimiento del federalismo, un balance provisional arroja que si bien desde el plano normológico se han dispensado cláusulas relevantes en aquella dirección, paralelamente existe un intenso déficit en la aplicación real de las mismas.

En otras palabras, no sólo no se ha robustecido el federalismo sino que ha crecido disfuncionalmente el centralismo, con el consecuente quebranto de la calidad democrática e institucional.

3. Tampoco se ha limitado la hegemonía del Poder Ejecutivo de la Nación, tal como también se pregonaba al momento de propiciar la modificación constitucional de 1994.

Lejos de ello, dicho poder se ha vigorizado, ha acentuado su injerencia sobre los restantes departamentos del Estado y ha avanzando sobre las autonomías provinciales, fundamentalmente de aquellos entes subestatales cuyos gobernantes no coinciden con el color político del gobierno nacional de turno, creciendo marcadamente la dependencia económico-financiera de las provincias respecto del régimen nacional central.

4. Ante semejante panorama, es irrecusable insistir en la necesidad de consolidar una interacción armónica de las instancias políticas de la estructura federal, sobre una matriz de colaboración y respeto mutuos para operativizar el principio de «lealtad federal».

5. Es igualmente imprescindible el cabal empeño político para buscar los consensos básicos que permitan perfilar los instrumentos de coordinación federal 
más adecuados en orden a integrar al Gobierno nacional, las provincias, la CABA (también indirectamente a los municipios), y cumplir los postulados de la $\mathrm{C} . \mathrm{N}$. optimizando jurídica y axiológicamente los criterios de reparto de los recursos coparticipables.

6. Debe destacarse el valor anticipatorio que en relación con la C. N. ha tenido desde 1985 el constitucionalismo provincial argentino, positivando numerosas instituciones, derechos fundamentales e instrumentos procesales constitucionales para operativizarlos, con varios años de precedencia vis-à-vis la innovación constitucional de 1994.

7. En el plano de los derechos humanos, la Carta magna nacional es, para las constituciones provinciales, un piso o umbral y no un tope o máximo.

De ello se desprende que, en uso de sus autonomías y siempre dentro de la esfera de sus atribuciones y jurisdicciones, pueden incluir derechos no consagrados en aquélla o acordar mayor nivel tuitivo a otros sí literalizados (o implícitos) en ella y el resto del bloque federal de derechos, compuesto —además de la C. N.- por los instrumentos internacionales sobre derechos humanos con jerarquía constitucional y las leyes nacionales.

8. La potestad de crear regiones para su desarrollo económico y social ofrece a las provincias buenas perspectivas de crecimiento. La implementación de regiones es una competencia provincial y tanto ésta como la surgente de la celebración de convenios internacionales deben realizarse «con conocimiento del Congreso nacional», lo que supone la inexistencia de obligación alguna de lograr el consentimiento, la aprobación ni la autorización del Poder Legislativo de la Nación, sino el deber de comunicar a éste, moviéndose siempre en el marco de sus competencias en aras de preservar el citado principio de «lealtad federal».

9. Las actividades que en la órbita internacional pueden desplegar las provincias se entienden a partir de una relectura de la concepción clásica de relaciones internacionales, separando el núcleo duro de éstas, reservado al poder central, del núcleo blando, que pueden llevar adelante tales entes subnacionales.

10. Como mutatis mutandi afirma García de Enterría respecto del contexto europeo, pero con valencia extrapolable a nuestro diseño federal, el respaldo que a todas las políticas vinculadas con la irrupción de los nuevos espacios económicos integrados, desde la UE al Mercosur y, más aún, la imposición real de una globalización de la economía que las nuevas técnicas hacen posible y las exigencias del desarrollo económico parecen imponer, prestan una perspectiva nueva y obligada a todo el movimiento de relocalización inexorable de los centros de decisión ${ }^{103}$.

103 GARCÍA DE ENTERRÍA, E., en el prólogo a la obra de HERNÁNDEZ, A. M., Integración y globalización: rol de las regiones, provincias y municipios, cit., p. XV. 
11. La integración regional importa, principalmente, dos desafíos fundamentales para las provincias: de un lado, alcanzar los objetivos del desarrollo económico y social y del desarrollo bumano, con la magnitud de los cambios políticos, económicos, educativos, culturales y sociales por afrontar, comenzando con una tarea de compatibilización de la legislación; y, por otro, cumplir con las obligaciones inherentes a la integración supranacional, como componentes de un Estado Parte del Mercosur ${ }^{104}$.

Los retos esbozados deberían tener como plataforma legitimante un federalismo de concertación, participativo y solidario, que permita una relación equilibrada de las instancias que componen la estructura federal y posibilite un proceso integrado de crecimiento y evolución ad intra y ad extra.

12. A los fines de una cabal protección de los derechos humanos en los Estados de estructura compleja como el argentino, deben interpretarse conjuntamente los arts. 1.1, 2 y 28 de la CADH, ya que la denominada «cláusula federal» contenida en la última de las normas citadas pretende motorizar la obligación de respetar y garantizar aquellos derechos fundamentales sin que se diluya la responsabilidad internacional del Estado nacional.

13. La obligación de los jueces y demás autoridades públicas concernidos en punto a llevar adelante el «control de convencionalidad» en los ámbitos internos alcanza por igual a Estados unitarios o centralizados y federales o descentralizados pertenecientes al sistema tutelar interamericano; es decir que aquel deber no queda condicionado por el tipo de organización estatal que se asuma.

14. Para que el alegado propósito de profundizar el modelo de descentralización política, funcional y territorial (que la reforma constitucional de 1994 exaltara) pueda corporizarse en la realidad, debe tener como necesario correlato una sincera y consistente voluntad política. De lo contrario, las medidas que se pensaron para fortalecer el federalismo no pasarán de ser una muestra más de gatopardismo ${ }^{105}$, es decir, cambiar todo para que todo continúe igual.

104 HERNÁNDEZ, A. M., Integración y globalización: rol de las regiones, provincias y municipios, cit., p. 60.

${ }^{105}$ En la conocida novela El Gatopardo consta un diálogo entre Tancredi y su tío Fabrizio Salina, donde aquél, al comentarle que se había sumado al complot contra el rey de Italia pidiendo la república, le dice: «Si queremos que todo siga como está, es necesario que todo cambie» (LAMPEDUSA, G., El Gatopardo, Buenos Aires, Longseller, trad. de Dalia G. Sonatore de Acero, 2001).

Sobre la base de lo allí manifestado ha surgido (por ejemplo, en ciencias políticas) la expresión «gatopardismo», para referirse a la actitud de quienes íntimamente contrarios al cambio, paradójicamente lo promueven para que en realidad nada cambie; o, lo que es lo mismo, a quienes ceden o modifican una parte de las estructuras para mantener el todo sin que verdaderamente nada se modifique o altere. 
En el fondo, y una vez más, se hace aquí presente la necesidad del facta non verba, premisa irrecusable si verdaderamente se desea transitar con provecho los nuevos senderos del federalismo ${ }^{106}$ y superar $-\mathrm{O}$ al menos mitigar- las fuertes asimetrías de los diversos componentes de la estructura federal.

Title:

A LOOK AT THE ARGENTINE FEDERALISM: SPEECH AND REALITY

\section{Summary:}

I. Purpose of the work. II. The proposed itinerary. III. Brief general remarks. IV. Clarification of constitutional history. V. The federal system in Argentina. VI. Federalism and constitutional reform of 1994. VII. About the areas of concern (sometimes conflicting) in the field of federal structure. VIII. Additional considerations. IX. Epilogue.

\section{Resumen:}

Básicamente, este trabajo intenta: (i) presentar la situación actual del federalismo argentino; (ii) examinar si en la realidad han quedado cumplidas las pautas establecidas por la reforma constitucional de 1994 para «fortalecerlo»; (iii) analizar algunas cuestiones de interés que emanan de la dinámica federal, por ejemplo: (a) acerca de si las constituciones provinciales pueden establecer más derechos que los contenidos en la Constitución nacional o dotar a los ya consagrados en ésta (y replicados en aquélla) de un caudal protectivo más fuerte, (b) sobre la «cláusula federal» incluida en determinados instrumentos internacionales sobre derechos humanos, como el Pacto de San José de Costa Rica, y (c) en relación con el impacto del control de convencionalidad en las relaciones federales; y, por último, (iv) visualizar las perspectivas que respecto del federalismo aparecen en el horizonte institucional de Argentina.

${ }^{106}$ La frase que cierra el trabajo está obviamente tomada del título de la obra de LA PERGOLA, A., Los nuevos senderos del federalismo, Madrid, CEC, 1994. 


\begin{abstract}
:
Basically, this paper attempts: (i) to present the current situation of argentine federalism; (ii) to examine whether in reality have been fulfilled the guidelines established by the constitutional reform of 1994 to «strengthen» it; (iii) to analyze some issues of interest arising from federal dynamics, for example: (a) whether provincial constitutions can establish more rights than those contained in the Federal Constitution or provide rights already enshrined in this (and replicated in those) a stronger protective flow; (b) about the «federal clause» included in certain international human rights instruments, such as the Inter-American Convention on Human Rights, and (c) in relation to the impact of the conventionality control in federal relations; and, finally, (iv) to try to capturing the perspectives of federalism contained in the argentinian institutional horizon.
\end{abstract}

\title{
Palabras clave:
}

Federalismo argentino. Reforma constitucional de 1994. Derechos fundamentales. Estado Nacional. Provincias. Ciudad Autónoma de Buenos Aires. Municipios. Cláusula federal. Control de convencionalidad.

\section{Key words:}

Argentine Federalism. Constitutional reform of 1994. Fundamental rights. National State. Provinces. Autonomous City of Buenos Aires. Municipalities. Federal clause in international human rights treaties. Conventionality control. 


